\title{
Gas-solid conversion in fluidised bed reactors
}

\author{
A. Gómez-Barea ${ }^{\text {a,* }}$, B. Leckner $^{\text {b }}$, D. Santana ${ }^{\text {c }}$, P. Ollero ${ }^{\text {a }}$ \\ a Bioenergy Group, Chemical and Environmental Engineering Department, Escuela Superior de Ingenieros, \\ University of Seville, Camino de los Descubrimientos s/n, 41092 Seville, Spain \\ ${ }^{\mathrm{b}}$ Department of Energy and Environment, Chalmers University of Technology, \\ S-412 96 Göteborg, Sweden \\ ${ }^{\mathrm{c}}$ Thermal and Fluid Engineering Department, Universidad Carlos III de Madrid, \\ Avda. de la Universidad 30, 28911 Leganés Madrid, Spain
}

\begin{abstract}
A simplified model for gas-solid reactions in fluidised bed (FB) is proposed. Such models already exist for catalytic gas-solid reactions (CGSRs), providing general description of the system in terms of main governing parameters. Expansion of this approach to non-catalytic gas-solid reactions (NCGSRs) is difficult, because the solid reactant takes part in the reaction. Therefore, FB reactor models for NCGSR are usually devised only for specific cases, and a general analysis has not been presented up to date. The present model allows analysis of different types of NCGSR in a generalised way, handling catalytic reactions as a particular, simpler, case. It is shown that the reactor behaviour can be described by three governing dimensionless parameters. Two additional parameters, quantifying the importance of diffusion effects in single particles are also identified, and their impact on reactor behaviour is analysed. Possible simplifications are explored. Model limitations, that is, assumption of isothermal bed and particle and the occurrence of only one reaction, are discussed. Examples are outlined to show the applicability of the method.
\end{abstract}

Keywords: Fluidised beds; Gas-solid reactions; Transport processes; Modelling; Non-catalytic reactions; Diffusion effects

\section{Introduction}

Many important processes, in which non-catalytic gas-solid reactions are involved, take place in fluidised bed. Typical applications are found in metallurgical and thermochemical conversion processes. Examples of metallurgical importance comprise the reduction of metals oxides (iron, nickel, etc.), roasting of ores of heavy metals in sulphide form, such as copper, nickel, zinc and lead. Thermochemical examples are combustion, gasification and pyrolysis of coal and biomass, including sulphur capture (in-bed desulphurisation) using mineral rocks, such as dolomite or limestone. To this class of processes belong also thermal decomposition reactions, fluorination of uranium and plutonium compounds, some granulation processes, etc. The optimisation and scale-up of these processes benefit greatly from modelling of the system. Detailed description of physical and

Abbreviations: $\mathrm{BFB}$, bubbling fluidised bed; CGSR, catalytic gas solid reaction; FB, fluidised bed; FDE, free of diffusion effects; NCGSR, non-catalytic gas solid reaction; SIM, sharp interface model; UCM, uniform conversion model.

* Corresponding author. Tel.: +34 95 4487223; fax: +34 954461775 .

E-mail address: agomezbarea@esi.us.es (A. Gómez-Barea). chemical processes occurring inside an FB for NCGSR is, however, a difficult task. Simple methods providing approximate solutions for first estimates are quite useful. For instance, an approximate description of gas-solid reactions in FB can be sufficient for selection of mode of gas-solid contact, preliminary design, and optimal operating conditions by sensitivity analysis. Such models already exist for CGSR in FB [1-4]. In this type of system, the solids are unchanged as reaction proceeds and bed removal is not usually undertaken during steady-state operation if the catalyst is not poisoned. In contrast, simple models have not been developed for NCGSR due to their complexity compared to their catalytic counterparts. Although many FB reactor models have been published, they are devised for specific reactions only. A general framework for simplified treatment of NCGSR is not yet available.

The performance of gas-solid reactions in FB has been described by several approaches. Early models treated the FB reactor as if the gas and solids were mixed, avoiding the multiphase nature of the bed. These 'single-phase' models assumed that the reactor performance was determined by the residence time of the gas. The breakthrough caused by the introduction of the two-phase theory proposed in the early 1950s, allowed 


\section{Nomenclature}

A Non-reactive component in the solids (ash or equivalent)

$A_{\mathrm{T}} \quad$ bed cross section $\left(\mathrm{m}^{2}\right)$

$\mathrm{Bi} \quad$ Biot number

c gas concentration $\left(\mathrm{mol} \mathrm{m}^{-3}\right)$

$\mathrm{C}$ reactive component in the solids

$D_{\mathrm{e}} \quad$ effective diffusivity of the reactant solid particle $\left(\mathrm{m}^{2} \mathrm{~s}^{-1}\right)$

$D_{\mathrm{t}} \quad$ bed diameter (m)

$D a_{\mathrm{p}} \quad$ Damköhler number at particle scale, defined in Eq. (30)

$D a_{\mathrm{R}} \quad$ Damköhler number at reactor scale, defined in Eq. (22)

$D a_{\mathrm{S}} \quad$ Damköhler number for the solid reactant, defined in Eq. (40)

$f \quad$ function

$f_{1}\left(x_{\mathrm{c} 0}, \lambda\right)$ function defined in Eq. (45)

$f_{2}\left(x_{\mathrm{c} 0}, \lambda\right)$ function defined in Eq. (48)

$F\left(x_{\mathrm{c}}\right)$ function expressing the dependence of $\mathrm{d} x_{\mathrm{c}} / \mathrm{d} t$ on $x_{\mathrm{c}}$ for any $\eta_{\mathrm{p}}$

$F_{i}\left(x_{\mathrm{c}}\right) \quad$ function expressing the dependence of $\mathrm{d} x_{\mathrm{c}} / \mathrm{d} t$ on $x_{\mathrm{c}}$ when $\eta_{\mathrm{p}}=1$ (kinetic regime)

$F_{0}, F_{1}$ inlet and outlet flowrate of solids $\left(\mathrm{kg} \mathrm{s}^{-1}\right)$

$g \quad$ acceleration of gravity $\left(\mathrm{m} \mathrm{s}^{-2}\right)$

$g\left(x_{\mathrm{c}}\right) \quad$ function expressing the change of effective diffusivity with $x_{\mathrm{c}}$

$\mathrm{G} \quad$ gas reactant

$H \quad$ height of the vessel containing the bed (m)

$k \quad n$ th-order kinetic coefficient in the kinetics $\left((-r)=k c^{n}\right)\left(\left(\mathrm{kgmol} \mathrm{m}^{-3}\right)^{1-n} \mathrm{~s}^{-1}\right)$

$k_{\mathrm{b}} \quad$ coefficient of interchange between bubble and emulsion $\left(\mathrm{s}^{-1}\right)$

$k_{\mathrm{G}} \quad$ external mass-transfer coefficient $\left(\mathrm{m} \mathrm{s}^{-1}\right)$

$K_{r} \quad$ kinetic coefficient accounting for gas concentration and temperature $\left(\mathrm{s}^{-1}\right)$

$L_{\text {equ }} \quad$ equivalent size of solid particle (m)

$L_{\mathrm{f}} \quad$ bed height $(\mathrm{m})$

$M \quad$ Thiele module, function of conversion

$M_{\mathrm{c}} \quad$ molecular mass of solid reactant $\left(\mathrm{kg} \mathrm{kgmol}^{-1}\right)$

$n \quad$ order of reaction

$N_{\mathrm{a}} \quad$ concentration efficiency, defined in Eq. (23)

NTU number of transfer units, defined in Eq. (24)

$p_{\mathrm{b}}\left(x_{\mathrm{c}}\right)$ distribution of conversion in the bed (mass basis)

$p_{0}, p_{1}$ distribution of conversion in the inlet and outlet streams (mass basis)

$\Delta P_{\mathrm{b}} \quad$ pressure drop across the bed $(\mathrm{Pa})$

$(-r) \quad$ intrinsic reaction rate per unit of particle volume $\left((-r)=k c^{n}\right)\left(\mathrm{kgmol} \mathrm{m}^{-3} \mathrm{~s}^{-1}\right)$

$r_{\mathrm{c}, \mathrm{b}} \quad$ overall rate of reaction in the bed $\left(\mathrm{kg} \mathrm{s}^{-1}\right)$

$(-R)$ observed reaction rate per unit of particle volume $\left(\mathrm{kgmol} \mathrm{m}^{-3} \mathrm{~s}^{-1}\right)$

$R\left(x_{\mathrm{c}}\right) \quad$ reactivity of solid reactant $\left(\mathrm{s}^{-1}\right)$

$R e_{\mathrm{p}} \quad$ particle Reynolds number

$s \quad$ dummy variable of integration

\begin{tabular}{|c|c|}
\hline Sh & Sherwood number \\
\hline$t$ & time $(s)$ \\
\hline$T_{\mathrm{b}}$ & bed temperature $(\mathrm{K})$ \\
\hline$u$ & gas velocity $\left(\mathrm{m} \mathrm{s}^{-1}\right)$ \\
\hline$V_{\mathrm{p}}$ & particle volume $\left(\mathrm{m}^{3}\right)$ \\
\hline$w_{\mathrm{b}}$ & mass of $\mathrm{A}$ and $\mathrm{C}$ in the bed $\left(w_{\mathrm{b}}=w_{\mathrm{A}}+w_{\mathrm{c}}\right)(\mathrm{kg})$ \\
\hline$w_{\mathrm{c}}$ & mass of solid reactant $(\mathrm{C})$ in the bed $(\mathrm{kg})$ \\
\hline$w_{\mathrm{Tb}}$ & total mass of the bed $\left(w_{\mathrm{Tb}}=w_{\mathrm{b}}+w_{\text {inert }}\right)(\mathrm{kg})$ \\
\hline$x_{\mathrm{c}}$ & conversion of solid reactant in a particle \\
\hline$x_{\mathrm{c}, \mathrm{b}}$ & average conversion of solids in the bed \\
\hline$X_{\mathrm{g}}$ & gas conversion \\
\hline$Y_{\mathrm{c} 0}$ & mass fraction of solid reactant in the feed \\
\hline$Y_{\mathrm{c}, \mathrm{b}}$ & mass fraction of solid reactant in the bed \\
\hline$z$ & axial coordinate \\
\hline \multicolumn{2}{|c|}{ Greek symbols } \\
\hline$\alpha$ & $\begin{array}{l}\text { dimensionless parameter at reactor level, defined } \\
\text { in Eq. (52) }\end{array}$ \\
\hline$\beta$ & dimensionless excess of flow, defined in Eq. (25) \\
\hline$\delta$ & $\begin{array}{l}\text { kinetic parameter in Eq. (60), also Dirac's delta } \\
\text { function }\end{array}$ \\
\hline$\varepsilon$ & porosity \\
\hline$\varepsilon_{\mathrm{b}}$ & bubble fraction $\left(\left(\mathrm{m}^{3}\right.\right.$ bubbles $)\left(\mathrm{m}^{-3}\right.$ bed $\left.)\right)$ \\
\hline$\eta_{\mathrm{e}}$ & external effectiveness factor \\
\hline$\eta_{\mathrm{i}}$ & internal effectiveness factor \\
\hline$\eta_{\mathrm{p}}$ & particle effectiveness factor \\
\hline$\eta_{\mathrm{ph}}$ & interphase effectiveness factor \\
\hline$\kappa$ & parameter defined in Eq. (59) \\
\hline$\lambda$ & dimensionless parameter defined in Eq. (41) \\
\hline$v$ & stoichiometric factor of the reaction \\
\hline$\xi$ & kinetic parameter (see Table 1) \\
\hline$\rho$ & density of solid $\left(\mathrm{kg} \mathrm{m}^{-3}\right)$ \\
\hline$\tau_{\mathrm{R}}$ & solid residence time $(\mathrm{s})$ \\
\hline$\Theta\left(x_{\mathrm{c}}\right)$ & function defined in Eq. (39) \\
\hline \multicolumn{2}{|c|}{ Subscripts } \\
\hline b & bubble, bed, average in the bed \\
\hline $\mathrm{c}$ & reactive component in the particle \\
\hline crit & critical \\
\hline e & emulsion \\
\hline $\mathrm{i}$ & intraparticle \\
\hline in & inlet \\
\hline out & outlet \\
\hline $\mathrm{p}$ & particle \\
\hline $\mathrm{r}$ & reaction \\
\hline s & surface \\
\hline 0 & initial, superficial \\
\hline
\end{tabular}

consideration of the multiphase nature of the FB by means of a simplified description of two phases, in which the solids and the gas were distributed in the bed. Thereafter the concept of 'contact time distribution' was recognized as a key factor for taking into account the time of gas contact with the solid reactant [2]. May [1], Orcutt et al. [3] and Davidson and Harrison [4] used the two-phase theory of fluidisation for calculation of gas conversion in various isothermal FB catalytic gas reactors. 
Table 1

Main models applied to NCGSR kinetics

\begin{tabular}{|c|c|c|c|c|}
\hline Name & Abbreviation & $F_{i}\left(x_{\mathrm{c}}\right)$ & $\Theta(X)$ & Reference \\
\hline Volumetric model & UCM & $1-x_{\mathrm{c}}$ & $-\ln \left(1-x_{c}\right)$ & {$[22]$} \\
\hline Grain model; or sharp interface model & GM (SIM) & $\left(1-x_{\mathrm{c}}\right)^{2 / 3}$ & $3\left(1-\left(1-x_{\mathrm{c}}\right)^{1 / 3}\right)$ & {$[23,24]$} \\
\hline Random pore model & RPM & $\left(1-x_{c}\right)\left(1-\xi \ln \left(1-x_{\mathrm{c}}\right)\right)$ & $(2 / \xi)\left(1-\xi \ln \left(1-x_{\mathrm{c}}\right)\right)^{1 / 2}$ & {$[25]$} \\
\hline Simons model & SM & $\left(1-x_{\mathrm{c}}\right)\left(x_{\mathrm{c}}+\xi\left(1-x_{\mathrm{c}}\right)\right)^{1 / 2}$ & $2 \operatorname{arctgh}\left((1-\xi) x_{\mathrm{c}}+\xi\right)^{1 / 2}$ & {$[26]$} \\
\hline Johnson model & $\mathrm{JM}$ & $\left(1-x_{\mathrm{c}}\right)^{2 / 3} \mathrm{e}^{\xi x_{\mathrm{c}}^{2}}$ & NAEF & [27] \\
\hline Dutta model & $\mathrm{DM}$ & {$\left[1 \pm 100 x_{\mathrm{c}}^{\xi_{1} \xi_{2}} \exp \left(-\xi_{2} x_{\mathrm{c}}\right)\right]\left(1-x_{\mathrm{c}}\right)$} & NAEF & {$[20]$} \\
\hline Gardner model & GM & $\left(1-x_{\mathrm{c}}\right) \mathrm{e}^{-\xi x_{\mathrm{c}}}$ & NAEF & [28] \\
\hline Chornet model & $\mathrm{CM}$ & $\sqrt{x_{\mathrm{c}}}\left(1-x_{\mathrm{c}}\right)$ & $2 \operatorname{arctgh}\left(\sqrt{x_{\mathrm{c}}}\right)$ & [29] \\
\hline Modified volumetric model & MVM & $\xi_{1}^{1 / 2} \xi_{2}\left(1-x_{\mathrm{c}}\right)\left[-\ln \left(1-x_{\mathrm{c}}\right)\right]$ & NAEF & {$[30]$} \\
\hline Traditional model & $\mathrm{TM}$ & $\begin{array}{l}\left(1-x_{\mathrm{c}}\right)^{\xi} \\
n\end{array}$ & $(\xi-1)^{-1}\left[(1-X)^{1-\xi}-1\right]$ & [31] \\
\hline Polynomial model & PM & $\sum \xi_{i} x_{\mathrm{c}}\left(1-x_{\mathrm{c}}\right)^{i}$ & NAEF & {$[32]$} \\
\hline
\end{tabular}

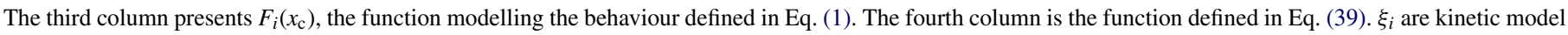
parameters; NAEF: not analytical expression found.

Extensive reviews have been published on modelling of FB reactors [2,5-7], where the analyses were performed with different degree of sophistication.

Several publications have surveyed the ability of FB reactor models in a variety of gas-solid reactions [5,8-11]. Generally, solutions of two-phase models based on isothermal catalytic systems have been presented in terms of two main dimensionless groups: one representing the dimensionless reaction rate and the other accounting for the interphase mass-transfer resistance [2,5-7]. Analytical solutions have been reported for simple kinetic schemes, such as first-, second-, etc., order kinetic (see for instance Table 11.5 in [2]). Solutions for more complex kinetics have been presented for catalytic reactions, based on conventional two-phase models and Kunii-Levenspiel's model $[12,13]$. Expansion to include thermal effects has also been undertaken in catalytic systems for simple reactions [7], but this extension causes difficulties because of the complexity of the treatment even for the simplest reaction scheme.

In FB catalytic systems the solids are unchanged as reaction proceeds (if no catalyst poisoning occurs) and the solids are only considered as a sink in the evaluation of the reaction rate. The reaction rate on the catalyst particle can be subjected to diffusion effects, but these do not change with time. For NCGSR in an FB, in contrast, the solid reactant is constantly consumed and solids make-up is required for steady-state operation. At any instant, the reactor contains particles that have spent different lengths of time inside the bed, and, thus, they have a wide burn-off distribution or particle age. During the course of reaction, the solid reactant contained in the particles is gradually affected, and the density and size of the particles change depending on the operating conditions in the bed. This behaviour can change from one particle-size fraction to another depending on the concentration of the solid reactant within the particles. A general description of the bed should account for variation in size and density of the reacting particles $[14,15]$. In addition to the aforementioned two main dimensionless groups appearing in the isothermal FB catalytic reactor, a third parameter taking into account the relative amounts of gas and solid reactants fed to the reactor is required to describe the NCGSR in an FB $[9,10]$.
The abbreviation NCGSR represents heterogeneous reactions where the active solid participates in the reaction, in contrast to catalytic systems, which, if not poisoned, remain unchanged during reaction. Some catalytic effects may exist anyway caused by the inert material, for instance, minerals in coal or biomass particles in thermochemical processes. However, such effects are included in the gas-solid kinetics (expression $\mathrm{d} x_{\mathrm{c}} / \mathrm{d} t$, see Eq. (1)) determined in the laboratory, in this way being an input to the model presented.

From this discussion it is clear that an FB reactor model for NCGSR should consider: (1) continuous bed removal; (2) variation of physical properties and reaction rate of single particles as reaction proceeds; (3) the distribution of conversion of the particles in the bed; (4) varying diffusion film and intraparticle mass-transfer limitations with burn-off. As a result, FB reactor models for catalytic reactions are not generally valid for NCGSR. The need for all these (and in some cases other) considerations is the reason why dedicated models have been developed for NCGSR in FB. Many reactor models exist, but they are devised solely for specific reactions. The reviews of Yates [16], Doraiswamy and Sharma [17], and Grace [2] survey the most popular models developed until the end of 1980s.

In the present work, a method is developed for the solution of NCGSR in an isothermal FB, allowing analysis of general NCGSR by a common procedure. In this way, the simple modelling approach already existing for catalytic systems is extended to non-catalytic systems. The treatment considers isothermal conditions both in the phases and within the reacting particles, which imposes some limitations to the application of the method. Furthermore, some NCGSRs imply consideration of various heterogeneous reactions, and this could limit the method further. This and other limitations are dealt with at the end of this work where extension of the method and possibilities to overcome limitations are discussed.

\section{Problem description and definitions}

Fig. 1 illustrates the problem dealt with. The gas reactant $G$ is introduced into the FB reactor as part of the fluidisation agent 


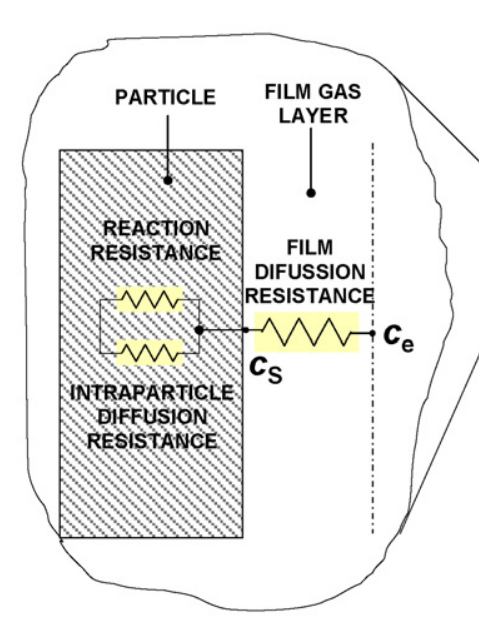

(a) PROCESSES IN A PARTICLE

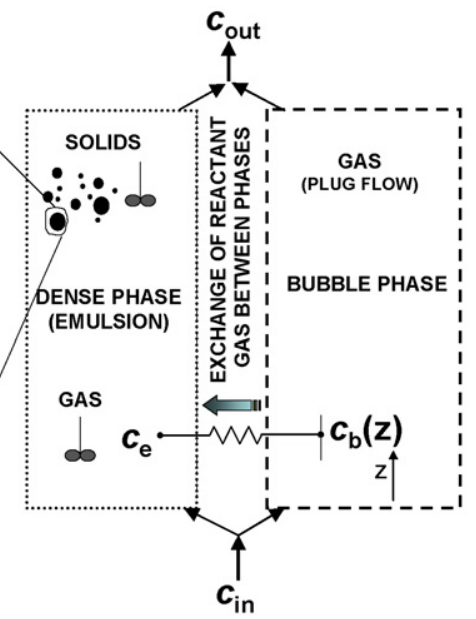

FB REACTOR MODEL

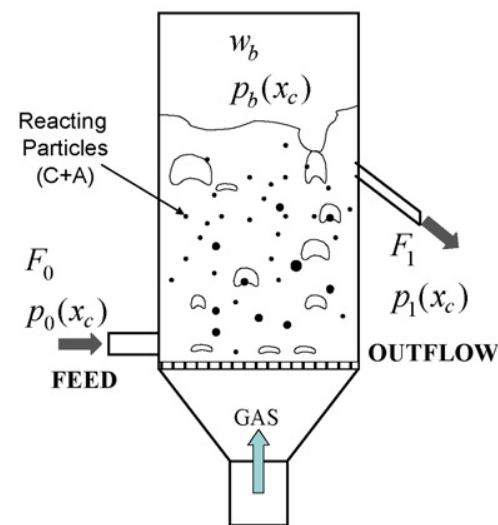

(b)

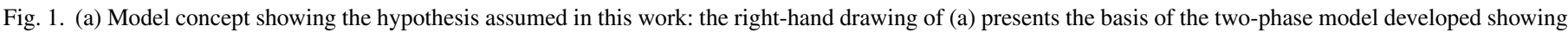

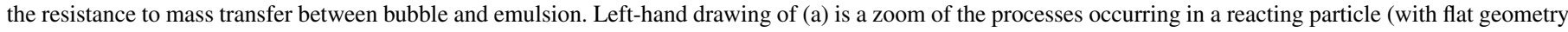

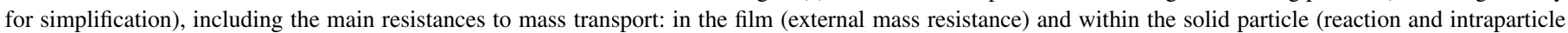
resistances). (b) Process scheme showing the contact pattern in an FB and population balance definitions.

with a concentration $c_{\text {in }}$. It passes through the bed as bubbles with a concentration $c_{\mathrm{b}}$, and through the well-mixed emulsion phase with a concentration $c_{\mathrm{e}}$. The $\mathrm{G}$ species is transferred from bubble to emulsion to reach the reacting sites within the reacting particles, where the reaction is $\mathrm{C}(\mathrm{s})+\nu \mathrm{G}(\mathrm{g}) \rightarrow$ products. The resistances of transport and reaction and the main assumptions that have been made to develop the mathematical model are shown in Fig. 1a. The resistances are: bubble to emulsion resistance, external film resistance around the solid particle (the resistance within the emulsion phase is assumed to be concentrated around the particles), and intraparticle resistance. The inlet and outlet streams of the solids including reactant $\mathrm{C}$ are shown in Fig. $1 \mathrm{~b}$, where the bed inventory, $w_{\mathrm{b}}$, is also specified. The reactor contains particles that have spent different times inside the bed and, thus, have a wide distribution of conversion, $p_{\mathrm{b}}\left(x_{\mathrm{c}}\right)$. This latter is considered equal to the distribution of the outflow stream, $p_{1}\left(x_{\mathrm{c}}\right)$, since perfect mixing of solid is assumed.

We assume that a solid particle $\mathrm{S}$, is made up of active solid reactant material $\mathrm{C}$ and non-reactive solid material $\mathrm{A}$, ash or similar. In addition, there could be inert material, fed to the system for various reasons (for instance, sand to keep the bed constant). The conversion of the solid reactant $\mathrm{C}$ contained in $\mathrm{S}$ at any instant, $x_{\mathrm{c}}$, is defined as the relative difference between the initial amount of $\mathrm{C}$ and the instantaneous one, $x_{\mathrm{c}}=\left(Y_{\mathrm{c} 0}\left(t_{0}\right)-Y_{\mathrm{c}}(t)\right) / Y_{\mathrm{c} 0}\left(t_{0}\right) . Y_{\mathrm{c}}$ is the mass fraction of solid reactant $\mathrm{C}$ in a given mass of material: $Y_{\mathrm{c} 0}\left(\mathrm{~kg} \mathrm{C} / \mathrm{kg} \mathrm{S}\right.$ at $\left.x_{\mathrm{c} 0}\right)$, and $Y_{\mathrm{c}}\left(x_{\mathrm{c}}\right)\left(\mathrm{kg} \mathrm{C} / \mathrm{kg} \mathrm{S}\right.$ at $\left.x_{\mathrm{c}}\right)$. Following these definitions $\left(1-Y_{\mathrm{c} 0} x_{\mathrm{c}}\right)$ is the mass fraction of $\mathrm{S}$ in a stream of conversion $x_{\mathrm{c}}$ and $Y_{\mathrm{c} 0} /\left(1-Y_{\mathrm{c} 0} x_{\mathrm{c}}\right)$ is $\mathrm{kgC}$ at $x_{\mathrm{c} 0} / \mathrm{kg} \mathrm{S}$ at $x_{\mathrm{c}}$. Note the difference between $Y_{\mathrm{c}}$ and $x_{\mathrm{c}}: Y_{\mathrm{c}}$ is an integral measure of the amount of $\mathrm{C}$ contained in a stream of material (or in the bed) containing various compounds $(\mathrm{C}+\mathrm{A}+$ inert $)$, whereas $x_{\mathrm{c}}$ is a mark of the state of conversion of an individual particle refereed to their initial state of conversion, when it was fed to the reactor, $x_{\mathrm{c} 0}$. Specification of $x_{\mathrm{c}}$ for a stream (or for the bed) has no meaning because, in the general case, in a given stream there will be particles with different degrees of conversion. However, the average of $x_{\mathrm{c}}$ in a stream (or in the bed) is uniquely related with $Y_{\mathrm{c}}$ (see Eq. (9)).

The rate of conversion of a single particle due to chemical reaction, under chemical reaction control, may be expressed as $[18,19]$ :

$\frac{\mathrm{d} x_{\mathrm{c}}}{\mathrm{d} t}=K_{r, \mathrm{e}} F_{i}\left(x_{\mathrm{c}}\right)$

$K_{r, \mathrm{e}}$ is the kinetic coefficient, accounting for the concentration of the gaseous reactant and temperature in the emulsion, where the reaction takes place. The function $F_{i}\left(x_{\mathrm{c}}\right)$ expresses the dependence of the conversion rate on $x_{\mathrm{c}} . K_{r, \mathrm{e}}$ is evaluated for the conditions in the emulsion, where the reaction takes place. The rate of reaction can also be formulated as [20,21]:

$\frac{\mathrm{d} x_{\mathrm{c}}}{\mathrm{d} t}=\frac{M_{\mathrm{c}}}{\rho_{\mathrm{c} 0}} \frac{k\left(x_{\mathrm{c}}\right) c_{\mathrm{e}}^{n}}{v}$

$k$ is the kinetic coefficient based on particle volume, and relates the rate of reaction per unit of volume with the gas reactant concentration, i.e. $(-r)=k c_{\mathrm{e}}^{n}$. This definition is typical in GSCR where $k$ is a constant for isothermal conditions. In contrast, for isothermal NCGSR $k$ depends on conversion. With the initial time as a reference, $F_{i}\left(x_{\mathrm{c}}=x_{\mathrm{c} 0}\right)=1$ and $k\left(x_{\mathrm{c}}\right)=k_{0} F_{i}\left(x_{\mathrm{c}}\right)$, so for $x_{\mathrm{c}}>x_{\mathrm{c} 0}$ one obtains from Eqs. (1) and (2):

$K_{r, \mathrm{e}}=\frac{M_{\mathrm{c}}}{\rho_{\mathrm{c} 0}} \frac{k_{0} c_{\mathrm{e}}^{n}}{v}$

When diffusion plays a role the conversion rate of a particle is written as

$\frac{\mathrm{d} x_{\mathrm{c}}}{\mathrm{d} t}=\eta_{\mathrm{p}}\left(x_{\mathrm{c}}\right) F_{i}\left(x_{\mathrm{c}}\right) K_{r, \mathrm{e}}$

where the particle's effectiveness factor $\eta_{\mathrm{p}}\left(x_{\mathrm{c}}\right)$ accounts for the diffusion resistance at particle scale (the external gas film and 
the intraparticle resistance). Some authors have used expressions like Eq. (4) to estimate the role of internal diffusion [20,21]. $\eta_{\mathrm{p}}\left(x_{\mathrm{c}}\right)$ is defined as the ratio of the actual conversion rate of a particle to the rate free of diffusion effects (FDE):

$\eta_{\mathrm{p}}\left(x_{\mathrm{c}}\right)=\frac{\mathrm{d} x_{\mathrm{c}} / \mathrm{d} t}{\mathrm{~d} x_{\mathrm{c}} /\left.\mathrm{d} t\right|_{\mathrm{FDE}}}=\frac{\mathrm{d} x_{\mathrm{c}} / \mathrm{d} t}{F_{i}\left(x_{\mathrm{c}}\right) K_{r, \mathrm{e}}}$

Formally, the $F_{i}\left(x_{\mathrm{c}}\right)$ function should be free of diffusion limitations, i.e. it should be determined in the kinetically controlled regime. In this work $F_{i}\left(x_{\mathrm{c}}\right)$ is the ratio of available solid surface at a certain conversion $x_{\mathrm{c}}$ to that of a reference case, $x_{\mathrm{c} 0}$. Table 1 provides some accepted models of $F_{i}\left(x_{\mathrm{c}}\right)$ used for NCGSR reactions.

From Eq. (4) a function can be defined: $F\left(x_{\mathrm{c}}\right)=F_{i}\left(x_{\mathrm{c}}\right) \eta_{\mathrm{p}}\left(x_{\mathrm{c}}\right)$, yielding

$\frac{\mathrm{d} x_{\mathrm{c}}}{\mathrm{d} t}=K_{r, \mathrm{e}} F\left(x_{\mathrm{c}}\right)$

The overall mass rate of reaction $r_{\mathrm{c}, \mathrm{b}}$ in the entire bed is computed by

$r_{\mathrm{c}, \mathrm{b}}=\int_{x_{\mathrm{c} 0}}^{1} w_{\mathrm{b}} R(s) p_{\mathrm{b}}(s) \mathrm{d} s$

where $w_{\mathrm{b}}$ is the mass of $\mathrm{S}(\mathrm{A}+\mathrm{C})$ in the bed and $p_{\mathrm{b}}\left(x_{\mathrm{c}}\right)$ is the distribution of conversion in the bed (mass basis). The integrand $w_{\mathrm{b}} R\left(x_{\mathrm{c}}\right) p_{\mathrm{b}}\left(x_{\mathrm{c}}\right)$ is the rate of reaction of solid particles in the bed having a conversion between $x_{\mathrm{c}}$ and $x_{\mathrm{c}}+\mathrm{d} x_{\mathrm{c}} . R\left(x_{\mathrm{c}}\right)$ is the reactivity expressed as $\mathrm{kg} \mathrm{C}$ reacted/ $\mathrm{kg} \mathrm{S}$ at $x_{\mathrm{c}}$ and time:

$R\left(x_{\mathrm{c}}\right)=\frac{Y_{\mathrm{c} 0}}{1-Y_{\mathrm{c} 0} x_{\mathrm{c}}} \frac{\mathrm{d} x_{\mathrm{c}}}{\mathrm{d} t}=\frac{Y_{\mathrm{c} 0} K_{r, \mathrm{e}}}{1-Y_{\mathrm{c} 0} x_{\mathrm{c}}} F\left(x_{\mathrm{c}}\right)$

The solids can accumulate in the bed, depending on the net balance between the rates of feed, conversion, and removal of solids. A solid particle is fed into the reactor with an initial conversion $x_{\mathrm{c} 0}$ and it is removed from the bed with a conversion, $x_{\mathrm{c}, \mathrm{b}}$ (average conversion of perfectly mixed particles in the bed). The fraction of $\mathrm{C}$ in the bed, $Y_{\mathrm{c}, \mathrm{b}}(\mathrm{kg} \mathrm{C} / \mathrm{kg} \mathrm{S}$ in the bed) is [9]:

$Y_{\mathrm{c}, \mathrm{b}}=\frac{Y_{\mathrm{c} 0}\left(1-x_{\mathrm{c}, \mathrm{b}}\right)}{1-Y_{\mathrm{c} 0} x_{\mathrm{c}, \mathrm{b}}}$

Solving for $x_{\mathrm{c}, \mathrm{b}}$ gives

$x_{\mathrm{c}, \mathrm{b}}=\frac{Y_{\mathrm{c} 0}-Y_{\mathrm{c}, \mathrm{b}}}{Y_{\mathrm{c} 0}\left(1-Y_{\mathrm{c}, \mathrm{b}}\right)}$

The bed material consists of the solid reactant $\mathrm{C}$ and the material remaining after completing the reaction $\mathrm{A}$, ash or any other type of inert component originating from the feed stream. The mass of solid reactant $\mathrm{C}$ in the bed is the product of $w_{\mathrm{b}}$ and $Y_{\mathrm{c}, \mathrm{b}}$ obtained from Eq. (9):

$w_{\mathrm{c}}=w_{\mathrm{b}} Y_{\mathrm{c}, \mathrm{b}}$

If inert material is fed to the bed, or if a batch of such material is used to fill the bed initially (for instance sand as initial buffer in biomass thermochemical conversion processes), an additional mass balance for this material has to be formulated. The composition of the bed at a given time depends on the way of operation.
A detailed case by case analysis is out of the scope of the present treatment. In this work, at any instant, there are three amounts of materials in the bed: $w_{\mathrm{c}}, w_{\mathrm{A}}$, and $w_{\text {inert }} . w_{\mathrm{b}}$ is the sum of $w_{\mathrm{c}}$ and $w_{\mathrm{A}}\left(w_{\mathrm{b}}=w_{\mathrm{c}}+w_{\mathrm{A}}\right)$, whereas $w_{\mathrm{Tb}}$ includes also the inert $\left(w_{\mathrm{Tb}}=w_{\mathrm{c}}+w_{\mathrm{A}}+w_{\text {inert }}\right)$, which is known by, for instance, pressure measurements $\left(w_{\mathrm{Tb}}=\Delta P_{\mathrm{b}}\left(A_{\mathrm{T}} / g\right)\right) . w_{\text {inert }}$, if it exists, has to be calculated from an additional mass balance. The way to include this additional balance in parallel to the main problem is outlined in Section 4.3.

\section{Development of the model}

\subsection{Modelling approach}

A realistic representation of the bed should account for the variation in size and density of the reacting material, as in the treatments by Chen and Saxena [14] and Overturf [15]. The model proposed aims at simplifying this general treatment. The method is based on two main steps:

Step 1: Application of a fluid-dynamic model to a catalytic system. This model is derived without considering the non-catalytic nature of the reaction and the actual burn-off distribution in the bed.

Step 2: Allowance is made for the deviation from the catalytic case, considering the extent of conversion in the FB by a solids population balance, which is solved by a kinetic model for a single particle.

\subsection{FB reactor modelling for $C G S R$}

With the assumptions discussed in Fig. 1a molar balances for the gas in the bubble and emulsion phases lead to

$\beta u_{0} \mathrm{~d} c_{\mathrm{b}}=k_{\mathrm{b}} \varepsilon_{\mathrm{b}}\left(c_{\mathrm{e}}-c_{\mathrm{b}}\right) \mathrm{d} z$

$(1-\beta) u_{0}\left(c_{\text {in }}-c_{\mathrm{e}}\right)=\int_{0}^{L_{\mathrm{f}}} k_{\mathrm{b}} \varepsilon_{\mathrm{b}}\left(c_{\mathrm{e}}-c_{\mathrm{b}}\right) \mathrm{d} z+\frac{v r_{\mathrm{c}, \mathrm{b}}}{M_{\mathrm{c}} A_{\mathrm{T}}}$

The boundary conditions are

$c_{\mathrm{b}}(z=0)=c_{\mathrm{b}, \text { in }}=c_{\mathrm{in}}$

$c_{\mathrm{out}}=\beta c_{\mathrm{b}}\left(z=L_{\mathrm{f}}\right)+(1-\beta) c_{\mathrm{e}}$

The gas conversion $X_{\mathrm{g}}$ and the interphase effectiveness factor $\eta_{\mathrm{ph}}$ are defined by

$\eta_{\mathrm{ph}}=\left(\frac{c_{\mathrm{e}}}{c_{\mathrm{in}}}\right)^{n} \quad$ and $\quad X_{\mathrm{g}}=1-\frac{c_{\mathrm{out}}}{c_{\mathrm{in}}}$

Integrating Eqs. (12) and (13), taking Eq. (16) into account, gives [33]:

$\frac{\left(1-X_{\mathrm{g}} / N_{\mathrm{a}}\right)^{n}}{X_{\mathrm{g}} / N_{\mathrm{a}}}=\frac{N_{\mathrm{a}}}{D a_{\mathrm{R}}}$

where the parameters $D a_{\mathrm{R}}$ and $N_{\mathrm{a}}$ are defined in Eqs. (22) and (23). Combining Eqs. (16) and (17):

$X_{\mathrm{g}}=\left(1-\eta_{\mathrm{ph}}^{1 / n}\right) N_{\mathrm{a}}$ 
$D a_{\mathrm{R}}=\frac{X_{\mathrm{g}}}{\eta_{\mathrm{ph}}}$

These expressions can be combined to give

$\frac{D a_{\mathrm{R}}}{N_{\mathrm{a}}}=\frac{X_{\mathrm{g}} / N_{\mathrm{a}}}{\left(1-X_{\mathrm{g}} / N_{\mathrm{a}}\right)^{n}}$

$\frac{\left(1-\eta_{\mathrm{ph}}^{1 / n}\right)}{\eta_{\mathrm{ph}}}=\frac{D a_{\mathrm{R}}}{N_{\mathrm{a}}}$

Eqs. (18)-(21) provide two independent relationships for four quantities: $D a_{\mathrm{R}}, N_{\mathrm{a}}, X_{\mathrm{g}}$ and $\eta_{\mathrm{ph}} . D a_{\mathrm{R}}$ is the Damköhler number at reactor scale, expressing the relative importance of gas residence time and reaction time:

$D a_{\mathrm{R}}=\eta_{\mathrm{p}} D a_{\mathrm{R}, \text { in }} \quad$ with $\quad D a_{\mathrm{R}, \text { in }}=\frac{k c_{\mathrm{in}}^{n-1}}{u_{0} / L_{\mathrm{f}}}$

$D a_{\mathrm{R}}$ is known for a CGSR if diffusion effects are absent, i.e. $\eta_{\mathrm{p}}=1$ (kinetic regime) because $D a_{\mathrm{R} \text {,in }}$ is known. Here, we assume that the bed height $L_{\mathrm{f}}$ is known or can be determined by the pressure drop across the bed. In contrast, $D a_{\mathrm{R}, \text { in }}$ is not known for a NCGSR even when the particles are in the kinetic regime, because the concentration of the reacting particles in the bed is unknown. We shall deal with this matter below. $N_{\mathrm{a}}$ is the concentration efficiency in the one-dimensional bed, defined by

$N_{\mathrm{a}}=\frac{c_{\text {in }}-c_{\text {out }}}{c_{\text {in }}-c_{\mathrm{e}}}=1-\beta \exp \left(\frac{-\mathrm{NTU}}{\beta}\right)$

NTU is the number of transfer units and $\beta$ is the dimensionless excess gas flow:

$\mathrm{NTU}=\frac{k_{\mathrm{b}} \varepsilon_{\mathrm{b}}}{u_{0} / L_{\mathrm{f}}}$

$\beta=\frac{u_{0}-u_{\mathrm{mf}}}{u_{0}}$

The expression for $\beta$ assumes that all gas in excess of minimum fluidisation velocity flows through the bed in the form of bubbles. This rests on the "two-phase theory" of fluidisation [12]. There is evidence, however, that there is a short-cut flow through the bubbles, especially in larger particle systems. This has been quantified in several models and correlations and depends on the groups of $u_{\mathrm{b}} / u_{\mathrm{mf}}, u_{0} / u_{\mathrm{mf}}$ and $\varepsilon_{\mathrm{b}}$. Analyses of the throughflow in various two-phase models have been reviewed in $[4,5,12,34]$. The impact of throughflow on the prediction of gas conversion in simple and dynamic two-phase flow models was assessed by Mostoufi et al. [11]. A correction for throughflow could be needed when using $\beta$ in Eq. (23), especially for larger particle systems. Sensitivity studies employing the final reactor model are helpful in identifying the need for further refinement. In the cases outlined in this work, the results have been found insensitive to this parameter.

We conclude that the interphase effectiveness factor $\eta_{\mathrm{ph}}$ is only a function of the group $N_{\mathrm{a}} / D a_{\mathrm{R}}$, and $X_{\mathrm{g}}$ is a function of the two groups $N_{\mathrm{a}}$ and $N_{\mathrm{a}} / D a_{\mathrm{R}}$. The relationships needed to calculate NTU and $\beta$ and related parameters depend on the flow pattern and the particle system under consideration. Examples of formulae useful for bubbling fluidisation in lab-scale FB can be found in Table 1 [33]. Further information for other fluidisation systems and scales is found in $[12,34]$.

For reaction orders of $1,1 / 2$ and 2 explicit solutions for $\eta_{\mathrm{ph}}$ are found in the literature $[2,35]$. In a general case, for $n$ thorder kinetics, explicit solutions for $\eta_{\mathrm{ph}}$ as a function of $D a_{\mathrm{R}}$ and $N_{\mathrm{a}}$, can be obtained by Frank-Kamenetskii's approximation (see Appendix A) applied to Eq. (21):

$\eta_{\mathrm{ph}}=\left\{\begin{array}{l}\left(\left[\left\{(1-n)\left(D a_{\mathrm{R}} / N_{\mathrm{a}}\right)\right\}^{1 / n}+1\right]^{n}+n\left(D a_{\mathrm{R}} / N_{\mathrm{a}}\right)\right)^{-1} \\ \quad \text { with } 0<n \leq 1 \\ 2 n\left[(2 n)^{1 / n}-1+\left(1+2 n\left(D a_{\mathrm{R}} / N_{\mathrm{a}}\right)\right)^{1 / n}\right]^{-n} \\ \quad \text { with } 1<n \leq 2.7\end{array}\right.$

Once $\eta_{\mathrm{ph}}$ is known, the gas conversion is determined by Eq. (18) or (19).

\subsection{Modelling of particle kinetics in CGSR}

To calculate the particle effectiveness factor $\eta_{\mathrm{p}}$ in the catalytic case, we assume that $\eta_{\mathrm{p}}$ does not depend on $x_{\mathrm{c}}$ or, more useful for the later expansion to NCGSR, we consider that $x_{\mathrm{c}}=x_{\mathrm{c} 0}$. The estimation of $\eta_{\mathrm{p}}$ is achieved through an internal and an external effectiveness factor, $\eta_{\mathrm{i}}$ and $\eta_{\mathrm{e}}$, so that $\eta_{\mathrm{p}}=\eta_{\mathrm{i}} \eta_{\mathrm{e}}$. The detailed derivation of the equations needed and the way to obtain the necessary information from experiments have been published in [33]. The effectiveness factors for isothermal CGSR are written as

$$
\begin{aligned}
& \eta_{\mathrm{e}}=\left(\frac{c_{\mathrm{s}}}{c_{\mathrm{e}}}\right)^{n} \\
& \eta_{\mathrm{i}}=\frac{(-R)}{k c_{\mathrm{s}}^{n}}=\frac{1}{V_{\mathrm{p}} k c_{\mathrm{s}}^{n}} \int_{V_{\mathrm{p}}} k c^{n} \mathrm{~d} V_{\mathrm{p}}
\end{aligned}
$$

Under pseudo-steady-state conditions, the isothermal masstransfer problem for $n$ th-order kinetics can be expressed as

$\eta_{\mathrm{e}}=\left(1-D a_{\mathrm{pe}} \eta_{\mathrm{p}}\right)^{n}=\left(1-D a_{\mathrm{pe}} \eta_{\mathrm{i}} \eta_{\mathrm{e}}\right)^{n}$

where a second Damköhler number, $D a_{\mathrm{pe}}$, represents the ratio of the maximum diffusion rate (when $c_{\mathrm{s}}=c_{\mathrm{e}}$ ) to the reaction rate controlled by external diffusion (when $c_{\mathrm{s}} \sim 0$ ):

$D a_{\mathrm{pe}}=\frac{k L_{\mathrm{equ}} c_{\mathrm{e}}^{n}}{k_{\mathrm{G}} c_{\mathrm{e}}}$

Taking into account Eqs. (A.1), Eq. (29) can be approximately solved for $\eta_{\mathrm{e}}$ :

$\eta_{\mathrm{e}}= \begin{cases}{\left[\left(\left\{(1-n) D a_{\mathrm{pe}} \eta_{\mathrm{i}}\right]^{1 / n}+1\right)^{-n}+n D a_{\mathrm{pe}} \eta_{\mathrm{i}}\right]^{-1},} & 0<n<1 \\ 2 n\left[(2 n)^{1 / n}-1+\left(1+2 n D a_{\mathrm{pe}} \eta_{\mathrm{i}}\right)^{1 / n}+1\right]^{-n}, & 1<n<2.7\end{cases}$

By solving the reaction-diffusion problem for a reactant particle, an approximate solution for $\eta_{\mathrm{i}}$ is often used:

$\eta_{\mathrm{i}}=\frac{\tanh \left(M_{\mathrm{s}}\right)}{M_{\mathrm{s}}}$ 
$M_{\mathrm{S}}$ being a conversion-dependent Thiele module:

$M_{\mathrm{s}}=L_{\text {equ }}\left[\frac{n+1}{2} \frac{k c_{\mathrm{s}}^{n-1}}{D_{\mathrm{e}}}\right]^{1 / 2}$

It is well know that Eq. (32) is strictly valid for first-order kinetics in a slab, but nevertheless, the generalised Thiele module defined in Eq. (33) makes the use of Eq. (32) a reasonable approximation for any geometry (characterised by $L_{\text {equ }}$ ) and reaction order, $n[20,24,31,33,34]$.

In Eqs. (31) and (33) $M_{\mathrm{s}}$ and $D a_{\mathrm{pe}}$ are evaluated for surface (index ' $\mathrm{s}$ ') and emulsion (index ' $\mathrm{e}$ ') conditions, respectively. The gas concentrations in the emulsion and at the surface differ from the inlet concentration, so they are not a priori known. Therefore $M_{\mathrm{S}}$ and $D a_{\mathrm{pe}}$ should be related to known quantities, that is, they should be expressed as functions of quantities evaluated for gas inlet conditions (index 'in'). This is done by taking into account Eqs. (16) and (28), yielding

$D a_{\mathrm{pe}}=D a_{\mathrm{pin}}\left(\eta_{\mathrm{ph}}\right)^{(n-1) / n}$

$M_{\mathrm{S}}=M_{\mathrm{in}}\left(\eta_{\mathrm{ph}} \eta_{\mathrm{e}}\right)^{(n-1) / 2 n}$

Here $\eta_{\mathrm{ph}}$ is calculated by Eq. (26), and $\eta_{\mathrm{e}}$ and $\eta_{\mathrm{i}}$ by Eqs. (31) and (32) where $M_{\mathrm{s}}$ and $D a_{\mathrm{pe}}$ are calculated by Eqs. (34) and (35). There is a loop for $\eta_{\mathrm{ph}}$ and the scheme of solution is iterative. From this treatment it is clear that the dependence of $\eta_{\mathrm{p}}$ is in the form:

$\eta_{\mathrm{p}}=f\left(\eta_{\mathrm{ph}}, M_{\mathrm{in}}, D a_{\mathrm{pin}}, n\right)$

The algorithm of solution and the graphical solution of this system is presented below in Section 4. The extension to account for the effect of solid conversion state is developed in Section 3.5 .

\subsection{FB reactor modelling for NCGSR}

In the model developed above for CGSR $D a_{\mathrm{R}, \text { in }}$ was assumed to be known, given by the batch of catalyst in the bed and the properties of the catalyst. In NCGSR, on the other hand, $D a_{\mathrm{R}}$ is unknown, because neither the amount of solid reactant nor its distribution of conversion $p_{\mathrm{b}}\left(x_{\mathrm{c}}\right)$ in the bed are known. Consequently, a solids population balance should be formulated and solved. The definition of $D a_{\mathrm{R}}$ for NCGSR is better given in the following terms:

$D a_{\mathrm{R}}=\frac{\int_{\forall x_{\mathrm{c}} \in V_{\mathrm{b}}} w_{\mathrm{b}} R\left(x_{\mathrm{c}}\right) p_{\mathrm{b}}\left(x_{\mathrm{c}}\right) \mathrm{d} x_{\mathrm{c}}}{u_{0} A_{\mathrm{T}} c_{\mathrm{in}} M_{\mathrm{c}} / v}=\frac{r_{\mathrm{c}, \mathrm{b}}}{u_{0} A_{\mathrm{T}} c_{\mathrm{in}} M_{\mathrm{c}} / v}$

Fig. 1b shows the main aspects and the nomenclature used. The main conditions were already discussed in Section 3.2. An additional assumption is that all the fines are returned to the reactor: there is no carryover, and all particles leave with the exit ash discharge. Also, all particles are assumed to enter with the same conversion $x_{\mathrm{c} 0}$. The treatment follows the procedure developed by [36]. The present approach, however, expresses the equations in extent of conversion instead of time or particle size $[37,10]$. Following the nomenclature of Fig. 1a, a population balance over the reactor yields the distribution of the conversion of the solids (see Appendix B):

$p_{\mathrm{b}}\left(x_{\mathrm{c}}\right)=\frac{1}{D a_{\mathrm{s}}} \frac{1}{F\left(x_{\mathrm{c}}\right)} \frac{1-Y_{\mathrm{c} 0} x_{\mathrm{c}}}{1-Y_{\mathrm{c} 0} x_{\mathrm{c} 0}} \exp \left[\frac{-\Theta\left(x_{\mathrm{c}}\right)}{\lambda}\right]$

$\Theta\left(x_{\mathrm{c}}\right)$ being a function

$\Theta\left(x_{\mathrm{c}}\right)=\int_{x_{\mathrm{c} 0}}^{x_{\mathrm{c}}} \frac{\mathrm{d} s}{F(s)}$

Expressions for $\Theta\left(x_{\mathrm{c}}\right)$, associated with well-known kinetic models are included in Table 1. The two dimensionless parameters $D a_{\mathrm{s}}$ and $\lambda$ in Eq. (38) are defined as

$D a_{\mathrm{s}}=\frac{K_{r, \mathrm{e}} w_{\mathrm{b}}}{F_{0}}=K_{r, \mathrm{e}} \tau_{\mathrm{R}}$

$\lambda=\frac{K_{r, \mathrm{e}} w_{\mathrm{b}}}{F_{1}}=\frac{K_{r, \mathrm{e}} w_{\mathrm{b}}}{F_{0}-r_{\mathrm{c}, \mathrm{b}}}$

$D a_{\mathrm{S}}$ is the Damköhler number of the solid reactant, expressing the ratio of residence time of solids $\tau_{\mathrm{R}}=w_{\mathrm{b}} / F_{0}$ and reaction time $1 / K_{r, \mathrm{e}}$. Note that $D a_{\mathrm{s}}$ ranges from 0 to 1 (the $D a_{\mathrm{s}}=1$ case is when the particles are made up of $C$ entirely remaining in the bed just the time they need to react completely). The relation between $D a_{\mathrm{S}}$ and $\lambda$ is obtained through the normalisation equation [36]:

$\int_{x_{\mathrm{c} 0}}^{1} p_{\mathrm{b}}(s) \mathrm{d} s=1$

Eq. (42) is not satisfied, however, with the distribution calculated by Eq. (38) because $p_{\mathrm{b}}\left(x_{\mathrm{c}}\right)$ should include both particles having solid reactant left $(\mathrm{C}+\mathrm{A})$ and particles completely reacted that still remain in the bed (only consisting of A). In Eq. (42) this second class of solids is not accounted for. Caram and Amundson [9,10] showed that for an FB coal gasifier $(\mathrm{C} \equiv$ carbon $+\mathrm{A} \equiv \mathrm{ash})$ an ash balance could solve this apparent difficulty (equivalent to and replacing Eq. (42)). The following treatment uses the same approach as that in [10]. An ash (A) balance over the system yields

$\frac{1-Y_{\mathrm{c} 0} x_{\mathrm{c} 0}}{1-Y_{\mathrm{c} 0} x_{\mathrm{c}, \mathrm{b}}}=\frac{F_{0}}{F_{1}}=\left(\frac{D a_{\mathrm{s}}}{\lambda}\right)^{-1}$

The $\mathrm{C}$-concentration in the bed can be obtained by taking into account all particles having a C-concentration in the bed, $Y_{\mathrm{c}}(s)$ given by Eq. (9). Integration over the bed using the distribution in Eq. (38) gives

$Y_{\mathrm{c}, \mathrm{b}}=\int_{x_{\mathrm{c} 0}}^{1} Y_{\mathrm{c}}(s) p_{\mathrm{b}}(s) \mathrm{d} s=\frac{f_{1}\left(x_{\mathrm{c} 0}, \lambda\right)}{1 / Y_{\mathrm{c} 0}-x_{\mathrm{c} 0}} \frac{1}{D a_{\mathrm{s}}}$

where

$f_{1}\left(x_{\mathrm{c} 0}, \lambda\right)=\int_{x_{\mathrm{c} 0}}^{1} \frac{1-s}{F(s)} \exp \left[\frac{-\Theta(s)}{\lambda}\right] \mathrm{d} s$

Elimination of $x_{\mathrm{c}, \mathrm{b}}$ between Eqs. (43) and (44) yields

$\left(\frac{D a_{\mathrm{s}}}{\lambda}\right)=\frac{f_{1}\left(x_{\mathrm{c} 0}, \lambda\right) / \lambda+\left(1 / Y_{\mathrm{c} 0}-1\right)}{1 / Y_{\mathrm{c} 0}-x_{\mathrm{c} 0}}$ 
which is the equivalent to Eq. (42) and replaces that equation by accounting for the particles that have reached complete conversion and are still in the bed.

An alternative equation (equivalent to Eq. (46)) is found by combination of Eqs. (38) and (7) and taking into account Eqs. (8), (39) and (41) to give

$\frac{D a_{\mathrm{s}}}{\lambda}=\frac{1}{\lambda}-f_{2}\left(x_{\mathrm{c} 0}, \lambda\right) \frac{Y_{\mathrm{c} 0}}{1-Y_{\mathrm{c} 0} x_{\mathrm{c} 0}}$

where

$f_{2}\left(x_{\mathrm{c} 0}, \lambda\right)=\int_{x_{\mathrm{c} 0}}^{1} \exp \left[\frac{-\Theta(s)}{\lambda}\right] \mathrm{d} s$

Once $D a_{\mathrm{s}}, x_{\mathrm{c} 0}$ and $Y_{\mathrm{c} 0}$ are given, Eq. (46) or (47) provide one equation for $\lambda$ (or $D a_{\mathrm{s}} / \lambda$ ). The distribution $p_{\mathrm{b}}\left(x_{\mathrm{c}}\right)$ can be then calculated by Eq. (38), and the average conversion in the bed, Eq. (10), is computed by

$x_{\mathrm{c}, \mathrm{b}}=1-\frac{f_{1}\left(x_{\mathrm{c} 0}, \lambda\right)}{\lambda}$

From Eqs. (40) and (41) $r_{\mathrm{c}, \mathrm{b}}$ becomes

$r_{\mathrm{c}, \mathrm{b}}=\left(1-\frac{D a_{\mathrm{s}}}{\lambda}\right) F_{0}$

The overall mass balance on the solids and gas reactant and the stoichiometry of the reaction link the conversions of solids and gas. By equalling the rate of disappearance of solids, $r_{\mathrm{c}, \mathrm{b}} / M_{\mathrm{c}}$ with the rate of consumption of the gaseous reactant, $\left(c_{\text {in }}-c_{\text {out }}\right) u_{0} A_{\mathrm{T}} / v$ one obtains

$X_{\mathrm{g}}=\frac{1}{\alpha}\left(1-\frac{D a_{\mathrm{s}}}{\lambda}\right)$

where $\alpha$ is a dimensionless parameter defined by the stoichiometric ratio of the feed rates of the reactant gas and the solids:

$\alpha=\frac{u_{0} A_{\mathrm{T}} c_{\mathrm{in}} M_{\mathrm{c}}}{\nu F_{0}}$

Elimination of $f_{1}\left(x_{\mathrm{c} 0}, \lambda\right)$ by combination of Eqs. (46) and (49) enables to relate $x_{\mathrm{c}, \mathrm{b}}$ and $D a_{\mathrm{s}} / \lambda$ :

$x_{\mathrm{c}, \mathrm{b}}=x_{\mathrm{c} 0}+\left(\frac{1}{Y_{\mathrm{c} 0}}-x_{\mathrm{c} 0}\right)\left(1-\frac{D a_{\mathrm{s}}}{\lambda}\right)$

Eq. (53) establishes clearly the boundary limits of $D a_{\mathrm{s}} / \lambda$ which are obtained for the limiting cases $x_{\mathrm{c}, \mathrm{b}}=0$ and 1 :

$\left(\frac{D a_{\mathrm{s}}}{\lambda}\right) \in\left(\frac{1-Y_{\mathrm{c} 0}}{1-Y_{\mathrm{c} 0} x_{\mathrm{c} 0}}, \frac{1}{1-Y_{\mathrm{c} 0} x_{\mathrm{c} 0}}\right)$

$D a_{\mathrm{s}} / \lambda$ near zero means complete conversion of solids, whereas $D a_{\mathrm{s}} / \lambda$ close to unity stands for the case of null solid conversion. In the particular case when all particles enter the bed with $x_{\mathrm{c} 0}=0$ and $Y_{\mathrm{c} 0}=1, D a_{\mathrm{s}} / \lambda$ is equal to one minus the solid conversion that is attained in the bed, that is $1-x_{\mathrm{c}, \mathrm{b}}$. Thus, with $x_{\mathrm{c} 0}=0$ and $Y_{\mathrm{c} 0}=1, D a_{\mathrm{s}} / \lambda$ ranges from 0 to 1 . Elimination of $D a_{\mathrm{s}} / \lambda$ by combination of Eqs. (51) and (53) gives a relation between $X_{\mathrm{g}}$ and $x_{\mathrm{c}, \mathrm{b}}$ :

$X_{\mathrm{g}}=\frac{x_{\mathrm{c}, \mathrm{b}}-x_{\mathrm{c} 0}}{\alpha\left(1 / Y_{\mathrm{c} 0}-x_{\mathrm{c} 0}\right)}$

The parameter $D a_{\mathrm{S}}$ should be evaluated for emulsion conditions, i.e. $D a_{\mathrm{s}}=D a_{\mathrm{s}, \mathrm{e}}$, but the ratio $D a_{\mathrm{s}} / \lambda$ does not depend on the reference situation for which the gas conversion is evaluated (see Eqs. (40) and (41)). The known parameter is actually $D a_{\mathrm{s} \text {,in }}$ (evaluated for the inlet conditions), but according to Eq. (16) $D a_{\mathrm{s}}\left(=D a_{\mathrm{s}, \mathrm{e}}\right)$ can be derived from $D a_{\mathrm{s}, \text { in }}$ :

$D a_{\mathrm{s}}=D a_{\mathrm{s}, \text { in }} \eta_{\mathrm{ph}}$

Hence, $\eta_{\mathrm{ph}}$ has to be known to calculate $D a_{\mathrm{s}}$ for emulsion conditions. An expression for $\eta_{\text {ph }}$ results from Eqs. (18) and (51):

$\eta_{\mathrm{ph}}=\left[1-\frac{1}{N_{\mathrm{a}} \alpha}\left(1-\frac{D a_{\mathrm{s}}}{\lambda}\right)\right]^{n}$

Eqs. (51) and (53) allow the calculation of $X_{\mathrm{g}}=f\left(D a_{\mathrm{s}} / \lambda, \alpha\right.$, $\left.\eta_{\mathrm{ph}}\right)$ and $x_{\mathrm{c}, \mathrm{b}}=f\left(D a_{\mathrm{s}} / \lambda\right)$. Taking into account Eq. (57) gives $X_{\mathrm{g}}=f\left(D a_{\mathrm{s}} / \lambda, \alpha, N_{\mathrm{a}}\right)$ so the reactor behaviour is governed by three parameters: $D a_{\mathrm{s}} / \lambda, \alpha$, and $N_{\mathrm{a}} \cdot N_{\mathrm{a}}$ comes from the fluid dynamics (Eq. (23)), whereas $\alpha$ is obtained from available inputs (see Eq. (52)). The inventory of the bed, $w_{\mathrm{b}}$ is known, for instance, from measurements of pressure drop across the bed (see Section 4.3). The group $D a_{\mathrm{s}} / \lambda$ is obtained from Eq. (46) or (47). To apply these equations, the functions $f_{1}$ (or $f_{2}$ ) defined in Eqs. (45) and (48) require the value of $\Theta\left(x_{\mathrm{c}}\right)$, defined in Eq. (39). Therefore $F\left(x_{\mathrm{c}}\right)$ has to be integrated for all the degrees of conversion in the FB reactor. To undertake this estimation, a kinetic model should be established in order to have available the expressions $F_{i}\left(x_{\mathrm{c}}\right)$ and $\eta_{\mathrm{p}}\left(x_{\mathrm{c}}\right)$. To sum up: for the estimation of $D a_{\mathrm{s}} / \lambda$ by Eq. (46) or (47), a kinetic model should be formulated first and then solved for the conditions in the reactor.

\subsection{Modelling of particle kinetics in NCGSR}

For the non-catalytic case the reaction rate of a particle developed in Section 3.3 has to be expanded to include the effect of conversion. This leads to the solution of a time-dependent problem with a moving interface within a particle. The rate of shrinkage/expansion of a particle's external surface is difficult to generalise because it depends on the nature of the NCGSR. For instance, for gasification reactions, a threshold for the local conversion has been fixed at the instant when the ash layer of particle peels off $[38,39]$. This threshold condition allows theoretical computation of the particle's boundary at any time. The threshold depends on type of reactor, resistance of ash, and operating conditions. In a FB, for example, the removal of an ash layer may be caused by attrition. In contrast, for reactions where a solid product is formed, the relation between the molar volumes of reactant and product is usually employed, together with some empirical parameter, to determine the rate of change in volume (shrinkage or expansion) [17]. In general, empirical input is needed at some level. Exceptions to this are the well-known uniform conversion model (UCM) and the sharp interface model (SIM) as we shall see later on, representing limiting cases. In sit- 
uations where these extreme cases are not valid, general, but still simple, models could be applied. In the following such a model will be formulated using Eq. (4) together with an estimate of the effectiveness factor of the particle $\eta_{\mathrm{p}}\left(x_{\mathrm{c}}\right)$.

As in the catalytic case, $\eta_{\mathrm{p}}\left(x_{\mathrm{c}}\right)$ is composed of an internal and an external effectiveness factor, $\eta_{\mathrm{i}}\left(x_{\mathrm{c}}\right)$ and $\eta_{\mathrm{e}}\left(x_{\mathrm{c}}\right)$. These are defined for NCGSR in the following way:

$\eta_{\mathrm{e}}=\left(\frac{c_{\mathrm{s}}}{c_{\mathrm{e}}}\right)^{n}=\frac{K_{r, \mathrm{~s}}}{K_{r, \mathrm{e}}}, \quad \eta_{\mathrm{i}}=\frac{\mathrm{d} x_{\mathrm{c}} / \mathrm{d} t}{F_{i}\left(x_{\mathrm{c} 0}\right) K_{r, \mathrm{~s}}}$

As seen they depend on conversion. Eqs. (32) and (33) still apply. However, $M_{\mathrm{S}}$ and $D a_{\text {pe }}$ given by Eqs. (34) and (35) have to consider the effect of conversion, because $k, L_{\mathrm{equ}}, k_{\mathrm{G}}$ and $D_{\mathrm{e}}$ depend on it. The change with conversion can be followed by the variation in reaction rate, Eq. (4), and the change in diffusivity of the particle by $g\left(x_{\mathrm{c}}\right)$, a function of the local porosity $\varepsilon$, and $D_{\mathrm{e} 0}$, the initial effective diffusivity. An empirical equation for $g\left(x_{\mathrm{c}}\right)$ is usually accepted for gas-solid reacting systems $[33,40,41]$ :

$g\left(x_{\mathrm{c}}\right)=\frac{D_{\mathrm{e}}\left(x_{\mathrm{c}}\right)}{D_{\mathrm{e} 0}}=\left(\frac{\varepsilon\left(x_{\mathrm{c}}\right)}{\varepsilon_{0}}\right)^{\kappa}=\left[1+\left(\frac{1-\varepsilon_{0}}{\varepsilon_{0}}\right) x_{\mathrm{c}}\right]^{\kappa}$

To estimate the change of particle size with $x_{\mathrm{c}}$, an additional relation is required. The shrinkage of a particle during consumption is not included in $F_{i}\left(x_{\mathrm{c}}\right)$ that only measures the change of the internal surface. If a detailed model (integration inside the particle) is used, it is possible to establish the rate of shrinkage as shown by Srinivas and Amundson [38] and Morell et al. [39] for the case of gasification of coal particles. However, here we have formulated the model in terms of the global particle conversion $x_{\mathrm{c}}$, and the change in size with particle conversion cannot be calculated. Nevertheless, this information can be provided by a simple empirical equation:

$L_{\text {equ }}\left(x_{\mathrm{c}}\right)=L_{\mathrm{equ}, 0}\left(1-x_{\mathrm{c}}\right)^{\delta}$

where a judicious choice of the parameter $\delta$ gives $L_{\text {equ }}$ for any $x_{\mathrm{c}}$. Only in the limiting kinetic models, such as UCM and SIM, the assumption of an arbitrary value for $\delta$ is not necessary: UCM implies a constant particle size $(\delta=0)$ and in SIM, $\delta=1 / 3$. In between these two limiting situations, the more general progressive conversion model with changes in size and density can be applied by properly choosing a value of $\delta$ in the range of $0-1 / 3$.

Now, with the definitions given in Eqs. (30) and (33), and with Eqs. (4), (59) and (60), the initial value $D a_{\text {pin, } 0}$ can be related to $D a_{\text {pin }}\left(x_{\mathrm{c}}\right)$ and $M_{\text {in }, 0}$ to $M_{\text {in }}\left(x_{\mathrm{c}}\right)$ as

$D a_{\text {pin }}\left(x_{\mathrm{c}}\right)=D a_{\text {pin }, 0}\left[F_{i}\left(x_{\mathrm{c}}\right)\left(1-x_{\mathrm{c}}\right)^{(3 / 2) \delta}\right]$

$M_{\text {in }}\left(x_{\mathrm{c}}\right)=M_{\mathrm{in}, 0}\left[\left(\frac{F_{i}\left(x_{\mathrm{c}}\right)}{g\left(x_{\mathrm{c}}\right)}\right)^{1 / 2}\left(1-x_{\mathrm{c}}\right)^{\delta}\right]$

where a correlation for the external diffusion coefficient $k_{\mathrm{G}}$ of the type of $S h \propto R e_{\mathrm{p}}^{1 / 2}$ was used to derive Eq. (61) [43]. By Eqs. (31), (33), (61) and (62) the desired relationships are determined:

$D a_{\mathrm{pe}}\left(x_{\mathrm{c}}\right)=D a_{\mathrm{pin}, 0}\left[\left(\eta_{\mathrm{ph}}\right)^{(n-1) / n}\left(F_{i}\left(x_{\mathrm{c}}\right)\left(1-x_{\mathrm{c}}\right)^{(3 / 2) \delta}\right)\right]$
$M_{\mathrm{s}}\left(x_{\mathrm{c}}\right)=M_{\mathrm{in}, 0}\left[\left(\eta_{\mathrm{ph}} \eta_{\mathrm{e}}\right)^{(n-1) / 2 n}\left(\left(\frac{F_{i}\left(x_{\mathrm{c}}\right)}{g\left(x_{\mathrm{c}}\right)}\right)^{1 / 2}\left(1-x_{\mathrm{c}}\right)^{\delta}\right)\right]$

In conclusion, Eqs. (31) and (33) allow calculation of $\eta_{\mathrm{e}}$ and $\eta_{\mathrm{i}}$ and so $\eta_{\mathrm{p}}$. The quantities $M_{\mathrm{s}}$ and $D a_{\mathrm{pe}}$, appearing in these equations, are calculated by Eqs. (63) and (64). From this treatment it is clear that the dependence of $\eta_{\mathrm{p}}$ is in the form

$\eta_{\mathrm{p}}=f\left(\eta_{\mathrm{ph}}, M_{\mathrm{in}, 0}, D a_{\mathrm{pin}, 0}, F_{i}\left(x_{\mathrm{c}}\right), g\left(x_{\mathrm{c}}\right), \delta\right)$

being the NCGSR version of Eq. (36).

\section{Discussion}

\subsection{Solution for CGSR}

The explicit solution for $\eta_{\mathrm{ph}}$ found in Eq. (26), i.e. $\eta_{\mathrm{ph}}=f\left(D a_{\mathrm{R}} / N_{\mathrm{a}}, \eta_{\mathrm{p}}, n\right)$, is displayed in Fig. 2 by solid lines. It can be demonstrated that this solution includes as particular cases published analytical expressions, such as reported by [2] for the modified Orcutt model of irreversible reactions with $n=1 / 2,1$ and 2 (symbols in Fig. 2). The difference between the solid lines and the symbols is very small and entirely associated with Frank-Kamenetskii's approximation used to derive Eq. (26) from Eq. (21). In fact, Eq. (20) is equivalent to the solutions of Orcutt's model, but the present formulation provides an additional scheme for simple estimation of diffusion limitations at the particle scale and for expanding this scheme to NCGSR. The simplest case $(n=1)$ allows a straightforward physical interpretation of the solution. In this case the

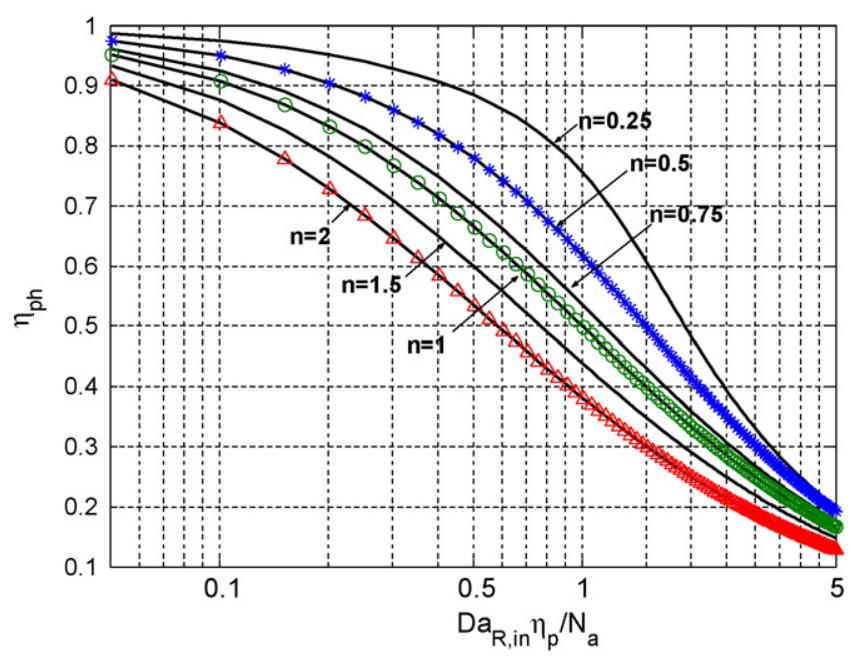

Fig. 2. Solution for gas-solid catalytic reactions in an FB drawn for the interphasic effectiveness factor, $\eta_{\mathrm{ph}}$ as a function of $D a_{\mathrm{R}, \text { in }} \eta_{\mathrm{p}} / \mathrm{N}_{\mathrm{a}}$ for various reaction orders, $n$ (between 0.25 and 2), according to Eq. (26). (Solid lines represent the present model, whereas symbol lines are results obtained from Orcutt's model.) The particle effectiveness factor $\eta_{\mathrm{p}}$ is unknown, so this figure must be used in parallel with Fig. 3 to determine iteratively $\eta_{\mathrm{p}}$ and $\eta_{\mathrm{ph}}$. 
solution is

$\eta_{\mathrm{ph}}=\frac{N_{\mathrm{a}} / D a_{\mathrm{R}}}{1+N_{\mathrm{a}} / D a_{\mathrm{R}}}, \quad X_{\mathrm{g}}=\frac{N_{\mathrm{a}}}{1+N_{\mathrm{a}} / D a_{\mathrm{R}}}$

The group $N_{\mathrm{a}} / D a_{\mathrm{R}}$ expresses the drop in gas concentration between the entrance and the emulsion. Two factors are responsible for that drop: the consumption of the reactant along the bed and the resistance between the bubble and emulsion to the transfer of the reactant (bypassing of bubbles). This is the so-called fluid-dynamic resistance, caused by the multiphase nature of the bed. Thus, $N_{\mathrm{a}}$ shows if the fluid dynamics at reactor scale interact with kinetics. Limiting values of $N_{\mathrm{a}}$ are 0 and 1: full and no fluid-dynamic interference. If the conditions in the bed lead to $N_{\mathrm{a}} \ll 1\left(\eta_{\text {ph }} \sim 0\right)$, the fluid-dynamic effects at reactor scale are rate limiting, no matter how fast the kinetics are. Obviously, the gas conversion would be zero in this case. Conversely, if $N_{\mathrm{a}} \sim 1$ and $N_{\mathrm{a}} / D a_{\mathrm{R}} \sim 1 / D a_{\mathrm{R}}$, the heterogeneous flow pattern associated with the phases in the bed (the global heterogeneity or heterogeneity at reactor scale) loses importance for the reaction (but the heterogeneity at particle scale, remains to be analysed, as will be shown below). Substitution of $N_{\mathrm{a}}=1$ in Eq. (66) yields

$\eta_{\mathrm{ph}}=\frac{1}{1+D a_{R}}, \quad X_{\mathrm{g}}=\frac{D a_{\mathrm{R}}}{1+D a_{\mathrm{R}}}$

which clearly shows that the gas conversion could be calculated as a well-mixed reactor. This is a consequence of the assumption of a well-mixed gas in the emulsion (where the reactions occur). If we assume, in contrast, plug-flow for the gas in the emulsion, the solution for the gas conversion would be

$X_{\mathrm{g}}=1-\exp \left(-D a_{\mathrm{R}}\right)$

Fig. 3 shows the graphic solution, including the particle scale, of $\eta_{\mathrm{p}}=f\left(\eta_{\mathrm{ph}}, M_{\mathrm{in}, 0}, D a_{\mathrm{pin}, 0}, n\right)$ given in Eq. (36). The solution

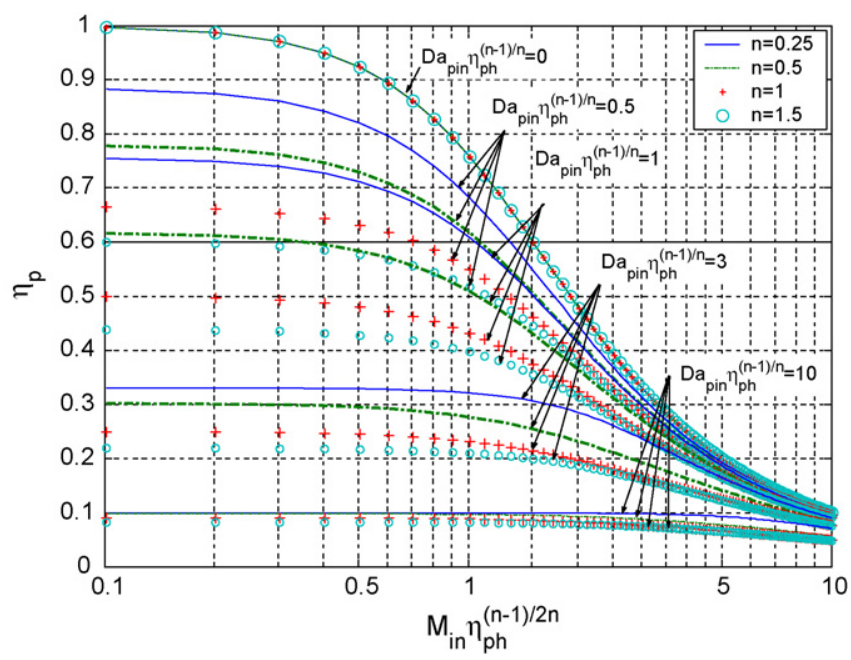

Fig. 3. Solution for gas-solid catalytic reactions in an FB (Eq. (36)) showing the particle effectiveness factor, $\eta_{\mathrm{p}}$ as a function of the parameters: $D a_{\text {pin }}, M_{\text {in }}$ and $n$, as well as the interphasic effectiveness factor $\eta_{\mathrm{ph}}$, grouped into two main dimensionless parameters: $M_{\mathrm{in}} \eta_{\mathrm{ph}}{ }^{(n-1) / 2 n}$ and $D a_{\mathrm{pin}} \eta_{\mathrm{ph}}{ }^{(n-1) / n}$. The lines are constant $D a_{\mathrm{pin}} \eta_{\mathrm{ph}}{ }^{(n-1) / n}$. The interphasic effectiveness factor, $\eta_{\mathrm{ph}}$ is unknown, so this figure must be used in parallel with Fig. 2 to determine iteratively $\eta_{\mathrm{p}}$ and $\eta_{\mathrm{ph}}$. allows determination of the external and internal effectiveness factors $\eta_{\mathrm{e}}$ and $\eta_{\mathrm{i}}$ separately and so to obtain $\eta_{\mathrm{p}} . \eta_{\mathrm{ph}}$ is coupled to $\eta_{\mathrm{p}}$, and the general case, when diffusion in the particle is of concern, has to be solved iteratively. This is the reason why $\eta_{\mathrm{ph}}$ is included in Fig. 3. In the case of first-order kinetics with respect to the gaseous reactant, the simple relations $D a_{\mathrm{pe}}=D a_{\mathrm{pin}}$, and $M_{\mathrm{e}}=M_{\text {in }}$ hold, no matter the concentration drop between inlet and emulsion, i.e. independent of $\eta_{\mathrm{ph}}$. In the case of CGSR where $n$ is not equal to unity, it is best to start by solving $\eta_{\text {ph }}$, assuming, for instance, $\eta_{\mathrm{p}} \sim 1$ in Eq. (26) ( $\eta_{\mathrm{p}}$ has to be known to calculate $\left.D a_{\mathrm{R}}\right)$. If the calculated value of $\eta_{\mathrm{p}}$ is not unity, the procedure is repeated until convergence. In summary, Figs. 2 and 3 are the graphical solution of Eqs. (26), (31) and (32), allowing determination of gas conversion for CGSR in FB. For the case of NCGSR in FB, the procedure is more complex, as discussed below.

\subsection{Solution for NCGSR}

The strategy for a solution procedure is presented in Fig. 4. The figure first lists typical inputs required (bed geometry, operating conditions, etc.). After the direct inputs, some calculations yield the governing parameters $N_{\mathrm{a}}, \alpha, D a_{\mathrm{s}, \mathrm{in}}, D a_{\mathrm{pin}, 0}$ and $M_{\mathrm{in}, 0}$. $N_{\mathrm{a}}$ is obtained from the fluid-dynamic parameters NTU and $\beta$. NTU and $\beta$ are calculated by various correlations from a bibliography selected according to the design of an FB and the

$\underline{\text { Imputs }}$

Direct input

- Bed and distributor geometry

- Operational parameters: $T_{\mathrm{b}}$, gas stream $\left(u_{0}, c_{\text {in }}\right)$, solid feed $\left(F_{0}\left(x_{c 0} Y_{c 0}\right)\right)$, total bed inventory $\left(w_{\mathrm{b}}\right)$ and from $\mathrm{L}_{\mathrm{f}}, \mathrm{A}_{\mathrm{T}}$ (pressure drop across the bed)

- Stoichiometry of reaction (v)

- Gas-solid kinetics: $K_{r}, F_{i}\left(x_{c}\right)$

- Solid properties: solid reactant $\left(d_{\mathrm{c} 0}, \rho_{\mathrm{c} 0}\right)$, inert $\left(d_{\mathrm{s}}, \rho_{\mathrm{s}}\right)$, function of effective diffusivity behaviour: $g\left(X_{c}\right)$

Fluid-dynamic data (easy calculations from proper correlations):

- From fluid-dynamic correlations: $u_{\mathrm{mf}}, \varepsilon_{\mathrm{b}}, k_{\mathrm{b}}, L_{\mathrm{f}}$

- NTU (Eq. 24 ) and $\beta$ (Eq. 25)

Computation of governing parameters:

- $\mathbf{N}_{\mathbf{a}}$ from Eq.(23)

- $\boldsymbol{\alpha}$ from Eq.(52)

- Da $\mathbf{a}_{\text {sin }}$ from Eq.(40) with $K_{\mathrm{r}}$ evaluated at inlet conditions

- Da $a_{\text {pin }, 0}$ from Eq.(61) with $c=c_{\text {in }}$ and $x_{\mathrm{c}}=x_{\mathrm{c} 0}$

- $\mathbf{M}_{\mathbf{i n}, 0}$ from Eq.(62) with $c=c_{\text {in }}$ and $x_{\mathrm{c}}=x_{\mathrm{c} 0}$

\section{Procedure of solution}

Assume $\eta_{\mathrm{ph}}$ Compute for any $x_{\mathrm{c}}$

$\mathbf{D a}_{\mathbf{p e}}$ and $\mathbf{M}_{\mathbf{s}}$ from Eq.(63) and Eq.(64) $\boldsymbol{\eta}_{\mathrm{p}}\left(\boldsymbol{x}_{\mathrm{c}}\right): \eta_{\mathrm{p}}\left(x_{\mathrm{c}}\right)=\eta_{\mathrm{e}} \eta_{\mathrm{i}}\left(\boldsymbol{\eta}_{\mathrm{e}}\right.$ with Eq (31) and $\boldsymbol{\eta}_{\mathrm{i}}$ with Eq. (32)) Compute

$\left(\mathrm{Da}_{\mathrm{s}} / \lambda\right)$ from (Eq. 46 or Eq. 47$)\left(f_{1}\left(x_{\mathrm{c} 0}, \lambda\right)(\mathrm{Eq} .45)\right.$ or $\left.f_{2}\left(x_{\mathrm{c} 0}, \lambda\right)(\mathrm{Eq} .48)\right)$

Check $\eta_{\text {ph }}$ from Eq. (57) $\mathbf{X}_{\mathrm{g}}$ from Eq. (51)

\section{Main Output}

$\mathrm{X}_{\mathrm{g}}$ from Eq. (18), $x_{\mathrm{c}, \mathrm{b}}$ from Eq. (55)

Fig. 4. Method of solution for NCGSR showing inputs, solution procedure and main outputs (gas and solid conversion). References of the equations necessary for the evaluation. Three kinds of input are defined: those that can be determined directly from data (kinetics, FB hardware and operating conditions), inputs necessary for the model that can be calculated from proper fluid-dynamic correlations (these need to be selected from literature), and the inputs for direct introduction into the model: $N_{\mathrm{a}}, \alpha, D a_{\mathrm{sin}}, D a_{\mathrm{pin}, 0}$, and $M_{\mathrm{in}, 0}$. 
mode of operation. Input data needed for fluid-dynamic specification are based on the geometry of the bed and distributor together with the properties of the gas and the solids in the bed. The solution procedure has one loop because the concentration in the emulsion should be estimated in order to calculate $\eta_{\mathrm{p}}\left(x_{\mathrm{c}}\right)$. Thus, $\eta_{\mathrm{ph}}$ is determined by iteration. First, $\eta_{\mathrm{ph}}$ is assumed and $\eta_{\mathrm{p}}\left(x_{\mathrm{c}}\right)$ is determined through the kinetic particle model for any $x_{\mathrm{c}}$. Then the population balance for the solid reactant is solved to estimate $D a_{\mathrm{s}} / \lambda$ (Eq. (46) or (47)), i.e. the solution of $D a_{\mathrm{s}} / \lambda=f\left(\eta_{\mathrm{ph}}, M_{\mathrm{in}, 0}, D a_{\mathrm{pin}, 0} ; F_{i}\left(x_{\mathrm{c}}\right), g\left(x_{\mathrm{c}}\right), \delta\right)$. Once $D a_{\mathrm{s}} / \lambda$ has been found, Eq. (57) yields a new estimation of $\eta_{\mathrm{ph}}$. The procedure is repeated until $\eta_{\mathrm{ph}}$ converges. Once $\eta_{\mathrm{ph}}$ and $D a_{\mathrm{s}} / \lambda$ have been established, $X_{\mathrm{g}}$ and $x_{\mathrm{c}, \mathrm{b}}$ are calculated through Eqs. (18) and (53). In summary, $X_{\mathrm{g}}$, and $x_{\mathrm{c}, \mathrm{b}}=f\left(D a_{\mathrm{s}} / \lambda, \alpha, N_{\mathrm{a}}\right)$ and $D a_{\mathrm{s}} / \lambda=f\left(\eta_{\mathrm{ph}}, M_{\mathrm{in}, 0}, D a_{\mathrm{pin}, 0} ; F_{i}\left(x_{\mathrm{c}}\right), g\left(x_{\mathrm{c}}\right), \delta\right)$, so that, in general, $X_{\mathrm{g}}$, and $x_{\mathrm{c}, \mathrm{b}}=f\left(\alpha, N_{\mathrm{a}}, M_{\mathrm{in}, 0}, D a_{\mathrm{pin}, 0} ; F_{i}\left(x_{\mathrm{c}}\right), g\left(x_{\mathrm{c}}\right), \delta\right)$. Obviously, the scheme of solution described above is not the only one possible when facing a NCGSR in an FB. In fact, it represents just a typical problem of analysis where the gas and solid conversion are the main required outputs. Other situations with different input data may exist, for example: the gas conversion is known, for instance, through measurement of the $\mathrm{O}_{2}$ concentration in the flue gas from a FB combustor; then, the scheme of solution given above needs to be reconsidered conveniently according to this input.

Fig. 5 illustrates the diffusion effects within single particles, and their variation with conversion for the traditional kinetic model (TM, Table 1) $F_{i}\left(x_{\mathrm{c}}\right)=\left(1-x_{\mathrm{c}}\right)^{\xi}$. In particular, the figure

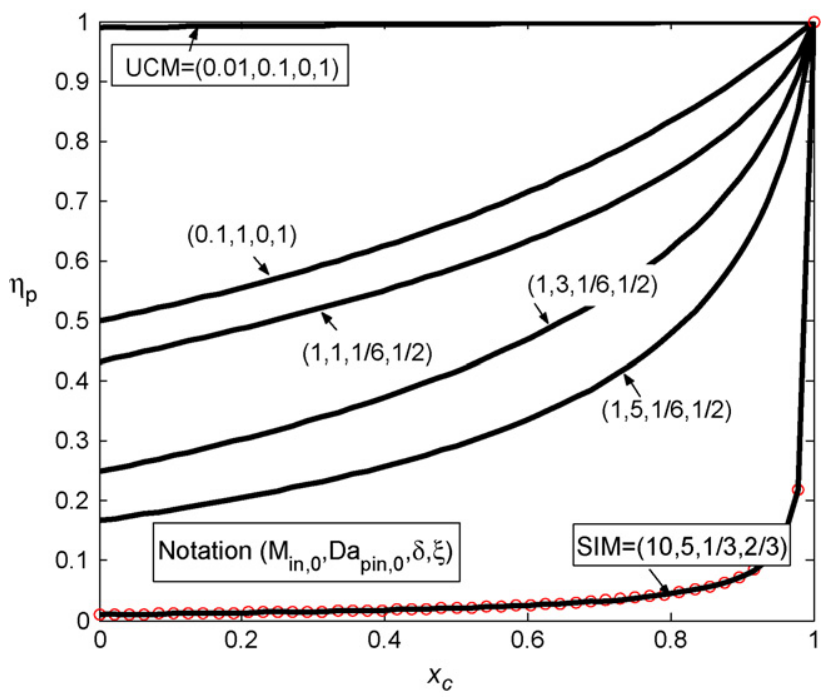

Fig. 5. Particle effectiveness factor, $\eta_{\mathrm{p}}$, vs. conversion, $x_{\mathrm{c}}$ for various values of the two main governing parameters at particle scale: $M_{\mathrm{in}, 0}$ and $D a_{\mathrm{pin}, 0}$, and the parameters $\delta$ (shrinking parameter) and $\xi$ (exponent of the traditional model). The brackets includes $M_{\mathrm{in}, 0}, D a_{\mathrm{pin}, 0}, \delta$, and $\xi$ used for the evaluation of the corresponding curve. All curves have been drawn for $n=1$ and $\eta_{\mathrm{ph}}=1$, using the traditional model $(\mathrm{TM})$, i.e. $F_{i}\left(x_{\mathrm{c}}\right)=\left(1-x_{\mathrm{c}}\right)^{\xi}$. The $g\left(x_{\mathrm{c}}\right)$ function (expressing the changes in effective diffusivity with conversion) used in all cases is given by Eq. (59) with $\kappa=2$. Two extreme cases of mass transport limitations are identified: extremely high limitations represented by the sharp interface model (SIM) and null limitations represented by uniform conversion model (UCM). These cases correspond to $\mathrm{SIM}=\left(M_{\mathrm{in}, 0} \gg 1, D a_{\text {pin }, 0}=\right.$ any, as long as $M_{\mathrm{in}, 0} \gg\left(D a_{\text {pin }, 0}\right)^{1 / 2}$, $\delta=1 / 3, \xi=2 / 3)$ and $\mathrm{UCM}=\left(M_{\mathrm{in}, 0} \ll 1, D a_{\text {pin }, 0} \ll 1, \delta=0, \xi=1\right)$. displays the solution of $\eta_{\mathrm{p}}=f\left(x_{\mathrm{c}}\right)$ for various values of $M_{\mathrm{in}, 0}$, $D a_{\mathrm{pin}, 0}, \delta$ and $\xi$, for $n=1, \eta_{\mathrm{ph}}=1$, and $g\left(x_{\mathrm{c}}\right)$ given by Eq. (59) with $\kappa=2$. Two extreme cases of diffusion effects are represented by the sharp interface model (SIM) (also called shrinking particle model or shrinking core exposed model) and the uniform conversion model. SIM is valid when the intraparticle resistance controls the overall reaction rate, so that for $M_{\mathrm{in}, 0} \gg 1$ and for $D a_{\text {pin, } 0}$ taking any value (as long as: $\left.M_{\mathrm{in}, 0}^{2} \gg\left(D a_{\mathrm{pin}, 0}\right)^{1 / 2}\right)$. This latter comes from the condition $B i_{\mathrm{in}, 0} \gg 1$ where $B i_{\text {in, }, 0}$ is the mass Biot number, $B i_{\mathrm{in}, 0}=M_{\mathrm{in}, 0}^{2} / D a_{\mathrm{pin}, 0}$. The UCM is valid for kinetic control cases, for $M_{\mathrm{in}, 0} \ll 1$ and $D a_{\mathrm{pin}, 0} \ll 1$. As shown, when a particle is described by the UCM, $\eta_{\mathrm{p}}$ is close to 1 for the whole range of $x_{\mathrm{c}}$. In contrast, under SIM most of the time $\eta_{\mathrm{p}}$ is close to zero and the overall rate of reaction is limited by intraparticle diffusion. The solution for $\eta_{\mathrm{p}}$ is simpler in these two limiting cases: diffusion does not play any role for UCM $\left(\eta_{\mathrm{p}} \rightarrow 1\right)$, whereas $\eta_{\mathrm{p}} \rightarrow 0$ for SIM being roughly independent of $x_{\mathrm{c}}$. Intermediate cases are drawn in Fig. 5 by varying $M_{\mathrm{in}, 0}$, $D a_{\text {pin, }, 0}$ as well as the shrinkage parameter $(\delta)$ and the kinetic parameters characterising $F_{i}\left(x_{\mathrm{c}}\right)$ (in this case values of $\xi$, in the $\mathrm{TM}$ ). For SIM $\delta=1 / 3$, whereas for UCM $\delta=0$. In general, the higher the values of $M_{\mathrm{in}, 0}$ and $D a_{\mathrm{pin}, 0}$, the higher the mass transport effects and, consequently, sharper profiles of $\eta_{\mathrm{p}}$ versus $x_{\mathrm{c}}$ are produced.

The solution for $\eta_{\mathrm{ph}}$ by Eq. (57) is displayed in Fig. 6 . Once $D a_{\mathrm{s}} / \lambda$ and $N_{\mathrm{a}} \alpha$ are established, $\eta_{\mathrm{ph}}$ is known. The curve $N_{\mathrm{a}} \alpha=1$ corresponds to the conversion $X_{\mathrm{g}}=\left(1-D a_{\mathrm{s}} / \lambda\right) / \alpha$ and $\eta_{\mathrm{ph}}=\left(D a_{\mathrm{s}} / \lambda\right)^{n}$. Fig. 6 allows visualization of two interesting limiting cases:

- Limiting case (a): In the region $N_{\mathrm{a}} \alpha<1$ the curves $N_{\mathrm{a}} \alpha=$ constant reach the horizontal axis $\left(\eta_{\mathrm{ph}}=0\right)$ at a $\left(D a_{\mathrm{s}} / \lambda\right)_{\text {crit }}$ with a value equal to $1-N_{\mathrm{a}} \alpha$, which corresponds also to a minimum threshold for $\lambda$ given by $\lambda_{\min }=D a_{\mathrm{s}} /\left(1-N_{\mathrm{a}} \alpha\right)$. An FB running with a given $N_{\mathrm{a}} \alpha$ and a $D a_{\mathrm{s}} / \lambda$ smaller than $1-N_{\mathrm{a}} \alpha$ is characterised by $\eta_{\mathrm{ph}} \rightarrow 0$ and so by a solution given by $X_{\mathrm{g}}=N_{\mathrm{a}}$ and $x_{\mathrm{c}, \mathrm{b}}=x_{\mathrm{c} 0}+N_{\mathrm{a}} \alpha$

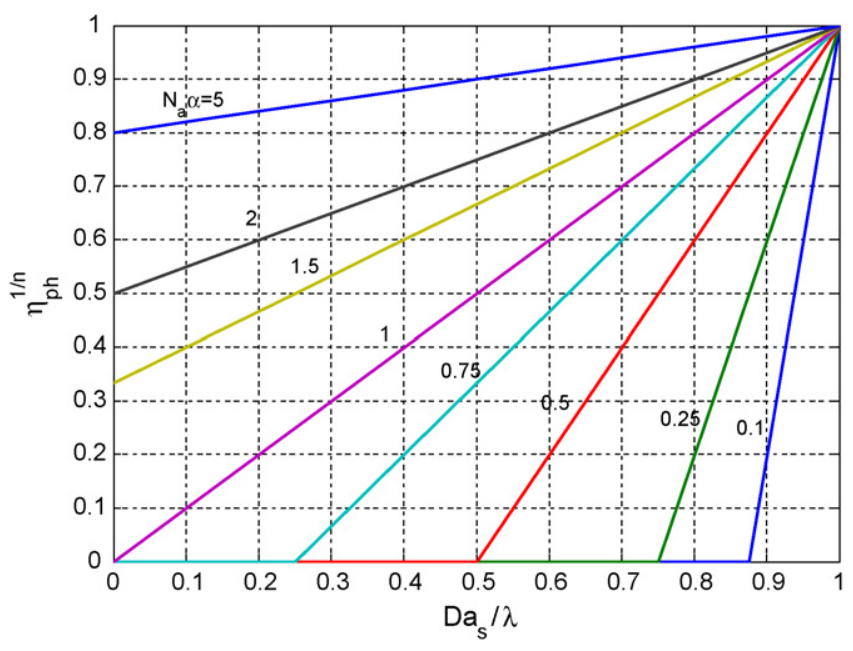

Fig. 6. Plot of interphasic effectiveness factor $\eta_{\mathrm{ph}}$, as a function of $D a_{\mathrm{s}} / \lambda$ taking various values of $N_{\mathrm{a}} \alpha$ (Eq. (57)). Observe that the dependence of the order of reaction, $n$ is included in the variable at the ordinate: $\eta_{\mathrm{ph}}^{1 / n}$. 

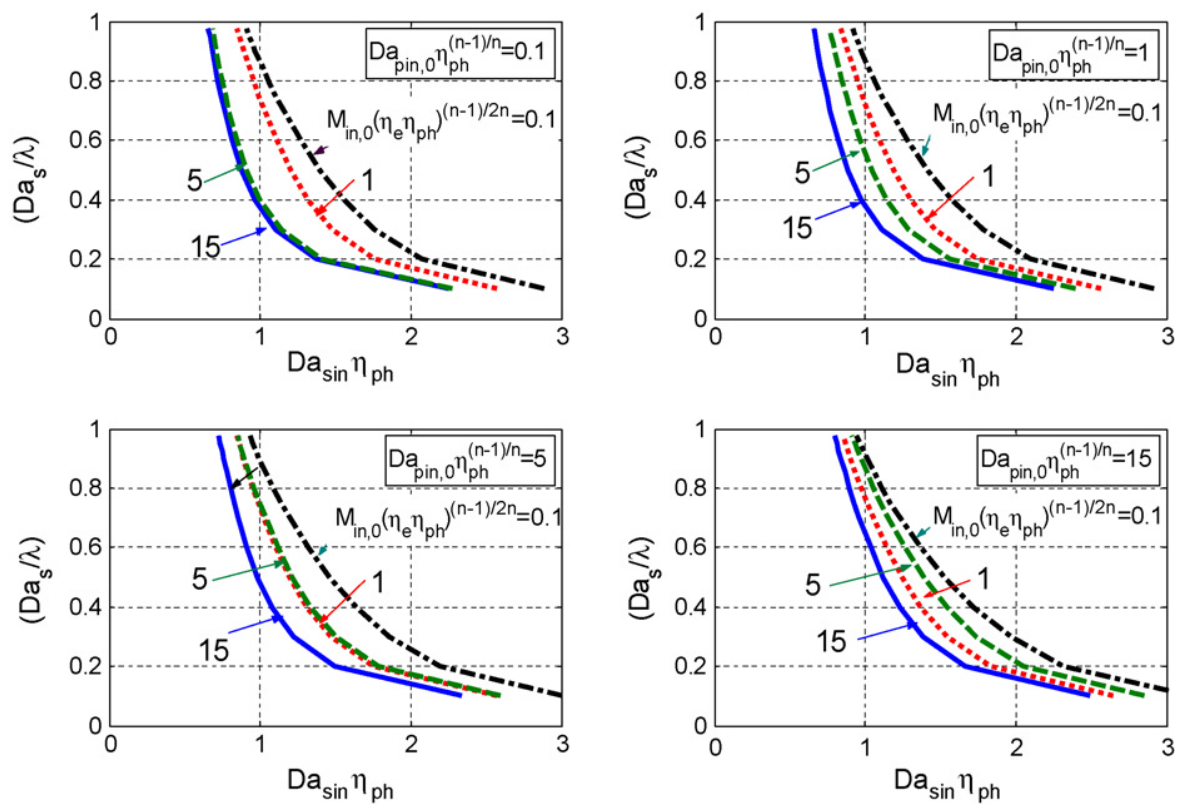

Fig. 7. $D a_{\mathrm{s}} / \lambda$ as a function of $D a_{\mathrm{sin}} \eta_{\mathrm{ph}}$ for various values of $D a_{\mathrm{pin}, 0} \eta_{\mathrm{ph}}^{(n-1) / n}$ and $M_{\mathrm{in}, 0}\left(\eta_{\mathrm{e}} \eta_{\mathrm{ph}}\right)^{(n-1) / 2 n}$ (all simulations have been run for TM with $\delta=1 / 6$ and $\left.\xi=1 / 2\right)$. The interphasic effectiveness factor, $\eta_{\mathrm{ph}}$ is unknown so this figure must be used with Fig. 6 to determine iteratively $\eta_{\mathrm{p}}$ and $\eta_{\mathrm{ph}}$.

$\left(1 / Y_{\mathrm{c} 0}-x_{\mathrm{c} 0}\right)$ (for instance, for the case $Y_{\mathrm{c} 0}=1$ and $x_{\mathrm{c} 0}=0$ this gives $x_{\mathrm{c}, \mathrm{b}}=N_{\mathrm{a}} \alpha$ ). In this region the feasibility of solution for $D a_{\mathrm{s}} / \lambda$ ranges from 0 to $1-N_{\mathrm{a}}$, however, the actual gas and solid conversion does not depend upon the actual value of $D a_{\mathrm{s}} / \lambda$. This case is, thus, dominated by the fluid-dynamic behaviour of the bed, $N_{\mathrm{a}}$, and the supply of gas relative to the solid, $\alpha$. This scenario only exists in the region $N_{\mathrm{a}} \alpha<1$ and, thus, for values of $\alpha<1$ (recall $N_{\mathrm{a}} \leq 1$ ). This case is said to be limited by the supply of gaseous reactant to the reacting particles. The conversion of solid is dictated by relative amount of gas entering the reactor $(\alpha)$, available for the particles in the emulsion $\left(N_{\mathrm{a}}\right)$, but not by kinetics of the gas-solid reaction or the solid reactant distribution in the bed $\left(D a_{\mathrm{s}} / \lambda\right)$. A population balance does not have to be solved in this case.

- Limiting case (b): The other limiting situation in the region $N_{\mathrm{a}} \alpha>1$ in Fig. 6 is in the points where the lines of $N_{\mathrm{a}} \alpha=$ constant reach the ordinate. Here, $D a_{\mathrm{s}} / \lambda=1 /\left(1-Y_{\mathrm{c} 0} x_{\mathrm{c} 0}\right)$ (for the simplest case $Y_{\mathrm{c} 0}=1$ and $\left.x_{\mathrm{c} 0}=0\right)$ the solid conversion is complete, $x_{\mathrm{c}, \mathrm{b}}=1, X_{\mathrm{g}}=1 / \alpha$, and $\eta_{\mathrm{ph}}=\left(1-1 /\left(N_{\mathrm{a}} \alpha\right)\right)^{n}$. This is even a simpler case than (a) because no matter what the conditions in the bed are, the solid is completely converted. Gas conversion is always smaller than unity, because $X_{\mathrm{g}}=1 / \alpha$, and $\alpha>1$ (recall $N_{\mathrm{a}} \alpha>1$ and $\left.N_{\mathrm{a}} \leq 1\right)$.

It is interesting to further analyse the limiting behaviour of the reactor with respect to $\alpha$. As $\alpha \ll 1$ the solids are in large excess and the system approaches the behaviour of a catalytic reactor. When this occurs, the two limiting cases identified above for CGSR (Section 4.1) apply. The parameters at reactor scale $N_{\mathrm{a}}$, and $D a_{\mathrm{R}}$ dominate the reactor behaviour. If the gas, in contrast, is in large excess $(\alpha \gg 1) X_{\mathrm{g}} \rightarrow 0$ and $\eta_{\mathrm{ph}} \rightarrow 1$ as $\eta_{\mathrm{ph}}=\left(1-1 / N_{\mathrm{a}} \alpha\right)^{n}$. This is the case where the differences in gas concentration between the emulsion and inlet stream can be neglected, and the kinetics at particle level determines the solid conversion. The cases discussed above for single particles hold (Section 3.5).

The computational scheme in Fig. 4, illustrates how $D a_{\mathrm{s}} / \lambda$ depends on $M_{\mathrm{in}, 0}, D a_{\mathrm{pin}, 0}$, and $n$, and in addition, on the form of $F_{i}\left(x_{\mathrm{c}}\right)$ and $g\left(x_{\mathrm{c}}\right)$. Fig. 7 shows this dependence of $D a_{\mathrm{s}} / \lambda$ on $M_{\mathrm{in}, 0}, D a_{\mathrm{pin}, 0}$, and $n$ for $\delta=1 / 6$ and $\xi=1 / 2$. The figure allows calculation of $D a_{\mathrm{s}} / \lambda$ from input data, provided that $\eta_{\mathrm{ph}}$ has been previously assumed. Therefore, this figure represents the internal iterative loop for $\eta_{\mathrm{ph}}$ described in Fig. 4. To enter at the horizontal axis in Fig. $7, \eta_{\text {ph }}$ has to be assumed. Once $D a_{\mathrm{s}} / \lambda$ is obtained from Fig. $7, \eta_{\mathrm{ph}}$ is calculated using Fig. 6. The iterative procedure is continued using Figs. 6 and 7 until convergence of $\eta_{\mathrm{ph}}$. The solution procedure for the general problem is then reduced to the use of Figs. 6 and 7, provided that the figures have been based on the proper kinetic model.

Figs. 6 and 7 are the NCGSR equivalents to Figs. 2 and 3. The main difference is that for CGSR, $\eta_{\mathrm{p}}$ does not depend on $x_{\mathrm{c}}$, and if only one representative $\eta_{\mathrm{p}}$ is to be calculated, an average particle size is taken as a reference. In the NCGSR case, the change of properties and reaction rates with $x_{\mathrm{c}}$ makes it necessary to follow the properties at different $x_{\mathrm{c}}$ and to integrate the contribution of all particles. This information is contained in one parameter: $D a_{\mathrm{s}} / \lambda$. In NCGSR the solution is not useful as a function of $D a_{\mathrm{R}}$, since, as shown in Eq. (22), this parameter depends on other parameters, which makes the solution difficult. Fig. 8 shows the solution of $D a_{\mathrm{R}}$ as a function of $\alpha, D a_{\mathrm{s}} / \lambda, N_{\mathrm{a}}$, and $n$.

\subsection{Simple approximate solution for NCGSR}

The procedure above considers a general distribution of particle conversion in the bed. Therefore the general solution is given in terms of $D a_{\mathrm{s}} / \lambda$ in Eq. (46) (or Eq. (47)). In some cases a simpler, approximate, solution can be derived, neglecting the 

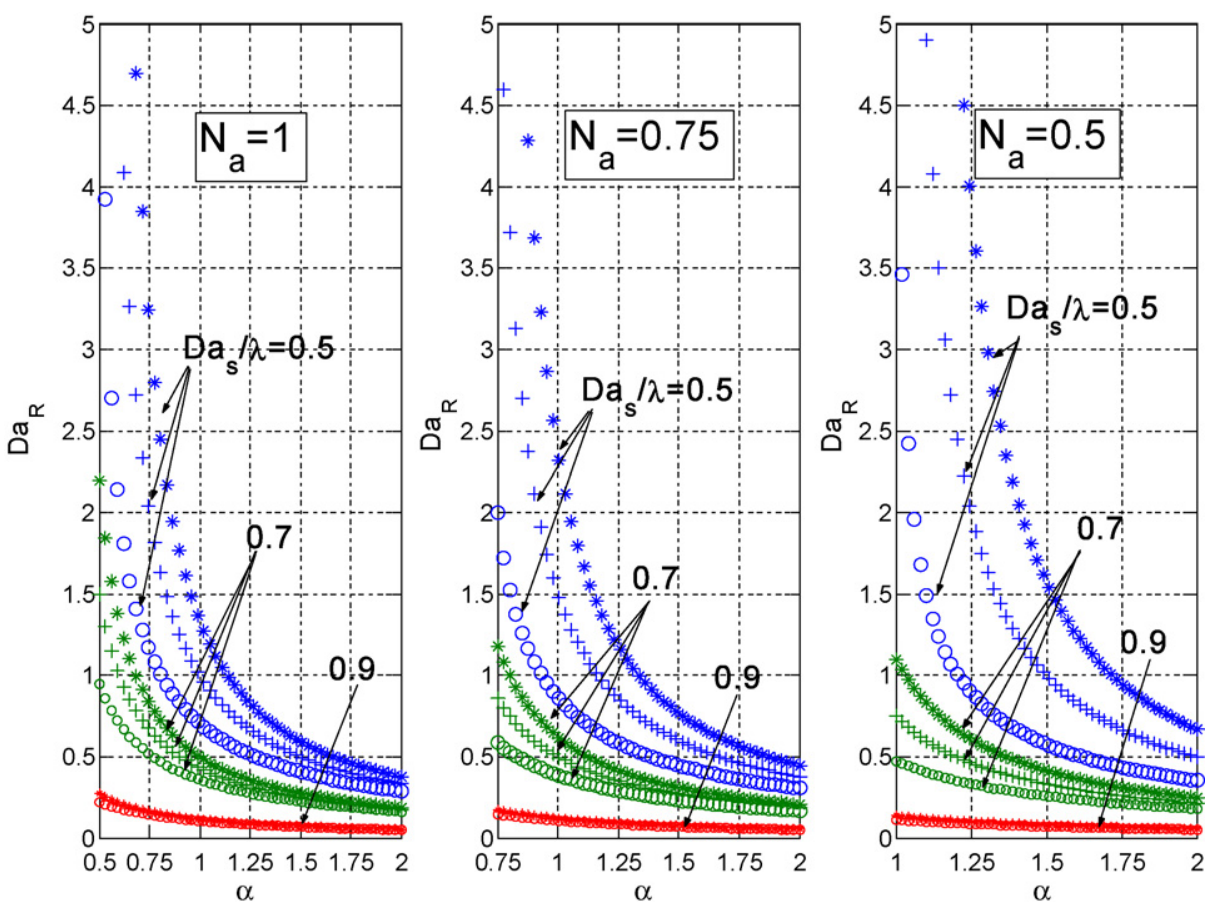

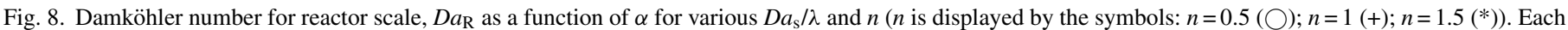
graph has been evaluated at different $N_{\mathrm{a}}: 1,0.75$ and 0.5 .

role of the distribution of conversion in the bed. To assess this approximation, a factor $\psi$ is formulated, defined as the ratio of the average reactivity in the bed to the reactivity evaluated at the average conversion:

$\psi=\frac{\int_{\forall x_{\mathrm{c}} \in V_{\mathrm{b}}} w_{\mathrm{b}} R\left(x_{\mathrm{c}}\right) p_{\mathrm{b}}\left(x_{\mathrm{c}}\right) \mathrm{d} x_{\mathrm{c}}}{w_{\mathrm{b}} R\left(x_{\mathrm{c}, \mathrm{b}}\right)}=\frac{r_{\mathrm{c}, \mathrm{b}}}{w_{\mathrm{b}} R\left(x_{\mathrm{c}, \mathrm{b}}\right)}$

Taking into account Eqs. (40), (41) and (46), Eq. (69) can be expressed as

$\psi=\frac{x_{\mathrm{c}, \mathrm{b}}-x_{\mathrm{c} 0}}{\lambda F\left(x_{\mathrm{c}, \mathrm{b}}\right)}$

When $\psi \sim 1$, the distribution of conversion of the particles has a small impact on the bed reactivity, and the tedious population balance is not necessary: the solution is considerably simplified. Application of the approximation $\psi=1$ to Eq. (70) yields

$\lambda=\frac{x_{\mathrm{c}, \mathrm{b}}-x_{\mathrm{c} 0}}{F\left(x_{\mathrm{c}, \mathrm{b}}\right)}$

Eq. (71) allows direct calculation of the unknown $\lambda$. Substitution of Eq. (71) into Eq. (53) yields an equation for evaluation of $x_{\mathrm{c}, \mathrm{b}}$ (no prior calculation of $D a_{\mathrm{s}} / \lambda$ is needed):

$\frac{\left(1 / Y_{\mathrm{c} 0}-x_{\mathrm{c}, \mathrm{b}}\right)\left(x_{\mathrm{c}, \mathrm{b}}-x_{\mathrm{c} 0}\right)}{F\left(x_{\mathrm{c}, \mathrm{b}}\right)}=D a_{\mathrm{s}}\left(\frac{1}{Y_{\mathrm{c} 0}-x_{\mathrm{c} 0}}\right)$

Gas conversion is then calculated by Eq. (55). The simplest situation is represented by UCM without diffusional effects, i.e. $F\left(x_{\mathrm{c}, \mathrm{b}}\right)=\left(1-x_{\mathrm{c}, \mathrm{b}}\right)$, giving the solution $x_{\mathrm{c}, \mathrm{b}}=D a_{\mathrm{s}}$ for the case $Y_{\mathrm{c} 0}=1$ and $x_{\mathrm{c} 0}=0$. The assessment of the simplification $\psi=1$ has been investigated for a general NCGSR by Heesink et al.
[18] and Caram and Amundson [10]. Heesink et al. elaborated a factor equivalent to $\psi$ and applied it to FB reactor modelling of sulphur capture by precalcined limestone. Caram and Amundson studied the effect of $\psi$ for SCM with and without deactivation (according to Johnson's model [27] for char gasification). In general, $\psi$ depends on $F\left(x_{\mathrm{c}}\right)$, but as a rule of thumb, the closer $x_{\mathrm{c}, \mathrm{b}}$ is to unity, the more $\psi$ deviates from unity. However, for UCM, i.e. $F\left(x_{\mathrm{c}}\right)=\left(1-x_{\mathrm{c}}\right), \psi=1$ holds, no matter the value of $x_{\mathrm{c}, \mathrm{b}}$. To see how much $x_{\mathrm{c}, \mathrm{b}}$ has to be below unity, Fig. 9 presents the solution of $\psi$ versus $x_{\mathrm{c}, \mathrm{b}}$ curves for various $F_{i}\left(x_{\mathrm{c}}\right)$ (see Table 1) in the case of gasification reactions. As seen, different kinetic models behave differently, but, broadly speaking, to model FB reactors working with an overall conversion higher than, say, $0.3-0.4$ above the entrance value $x_{\mathrm{c} 0}$, a population balance should be included in the case of one stage bed. For multistage bed cases, the last stage (s) $x_{\mathrm{c}, \mathrm{b}}-x_{\mathrm{c} 0}$ can take values below 0.3 and this simple case can be assumed. In a general case where there are diffusion effects within the reacting particles, $\eta_{\mathrm{p}}\left(x_{\mathrm{c}}\right)$ has to be accounted for, and the curves should be corrected accordingly. This procedure still provides great computational time saving, because it avoids the solution of Eq. (46) (or Eq. (47)).

\subsubsection{Examples of application for NCGSR}

4.3.1.1. Example 1: gasification of char with $\mathrm{CO}_{2}$ in a lab-scale $F B$. A lab-scale FB gasifier is fed with char using $\mathrm{N}_{2}-\mathrm{CO}_{2}$ gas mixtures as gasification agent. This example is chosen to show how to use the method to estimate gas and solid conversion and how to scale-up the kinetics from lab-scale, consistent with the approach derived for single particle behaviour. When 

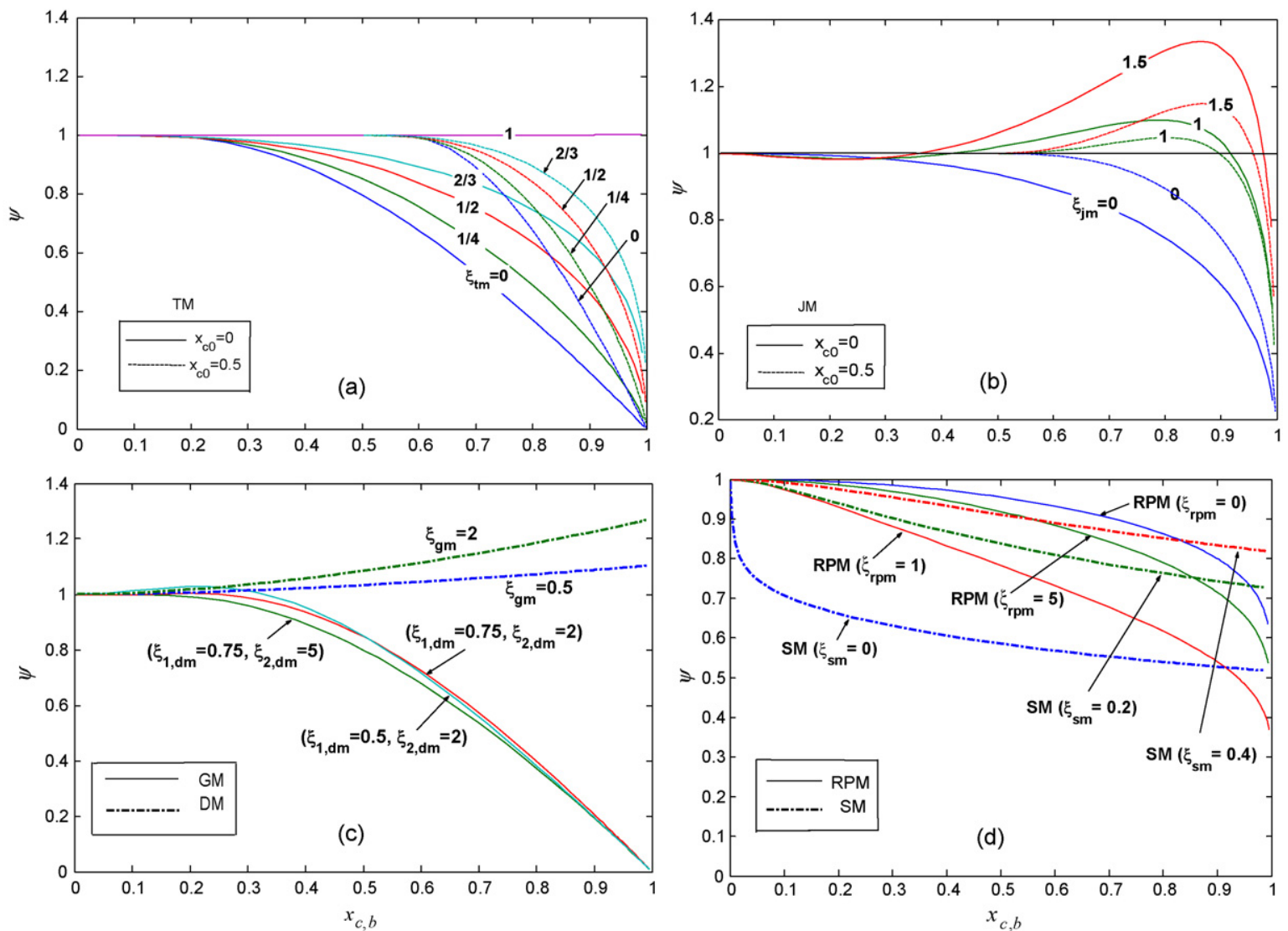

Fig. 9. $\psi$ vs. $x_{c, b}$ for various kinetic models of Table 1. Graph (a) and (b) traditional model (TM) and Johnson model (JM) for various model parameters $\xi$ at two initial conversions $\left(x_{\mathrm{c} 0}=0\right.$ (solid line) and $x_{\mathrm{c} 0}=0.5$ (dotted lines)). Graph (c) Gardner model (GM) (solid line) and Dutta model (DM) (dotted line), for $x_{\mathrm{c} 0}=0$ at various values of parameters $\xi$. Graph (d) presents random pore model (RPM) (solid line) and Simons model (SM) (dotted line), for $x_{\mathrm{c} 0}=0$.

treating char reactivity to simulate conversion in an FB, it is convenient to generate the char under conditions that are similar to those of the full-scale equipment. This is because the char reactivity could depend on the conditions under which the fuel particles were prepared, especially heating rate and temperature. Gómez-Barea et al. [42] determined the reactivity of an orujillo char with $\mathrm{CO}_{2}$ in a batchwise fed lab-scale FB reactor. Precautions were taken to avoid fluid-dynamics effects, such as bypassing of gas through large bubbles, and to maintain the conversion in the reactor low enough. Difficulties related to entrainment of solids when feeding powdery char at the top of the reactor made the authors use a char particle size of several $\mathrm{mm}$. Therefore, they first determined mass transport effects [43]. The rate of consumption of a char particle was measured for various sizes, $\mathrm{CO}_{2}$ concentration, temperature, and initial char batch. From the measurements, they calculated the evolution of $X_{\mathrm{g}}, \mathrm{d} x_{\mathrm{c}} / \mathrm{d} t$ and $x_{\mathrm{c}}$ with time. To determine $\eta_{\mathrm{p}}\left(x_{\mathrm{c}}\right), K_{r}$ and $F_{i}\left(x_{\mathrm{c}}\right)$, an empirical equation (Eq. (60)) was assumed to describe the evolution of particle size with conversion during the tests.

The first column of Table 2 provides data for the simulation of the lab-scale BFB. The objective of this simulation is to analyse the behaviour of the FB reactor in a continuous mode to retrofit the facility for steady-state tests. $\operatorname{UCM}\left(F_{i}\left(x_{\mathrm{c}}\right)=\left(1-x_{\mathrm{c}}\right)\right.$ and $\delta=0$ ) was chosen as kinetic model to represent the single particle behaviour. The governing parameters at reactor scale, $\alpha, N_{\mathrm{a}}$, and $D a_{\mathrm{s}, \text { in }}$, can be directly calculated. At char particle scale, the Thiele module $M_{\mathrm{in}, 0}$, and the Damköhler number $D a_{\text {pin, } 0}$ can be evaluated for inlet conditions. These five groups are listed in Table 2. From these parameters $D a_{\mathrm{s}} / \lambda$ can easily be calculated or read from Figs. 6 and 7 by iteration with $\eta_{\mathrm{ph}}$. Once these values have converged, $X_{\mathrm{g}}$ and $x_{\mathrm{c}, \mathrm{b}}$ are calculated through Eqs. (51) and (53). These values are presented at the bottom part of the left-hand column of Table 2 . The structure of the calculation given in Table 2 is shown in Fig. 4. Any other example can be solved in a similar way. It is worth noting that the solution obtained is one of the limiting cases discussed in Fig. 6 (case (a)). In fact, the value of $\left(D a_{\mathrm{s}} / \lambda\right)$ is nearly $\left(D a_{\mathrm{s}} / \lambda\right)_{\text {crit }}$ and $\eta_{\mathrm{ph}} \rightarrow 0, X_{\mathrm{g}} \rightarrow 1$. Finally, $F_{i}\left(x_{\mathrm{c}}\right)$ and $K_{r}$ and $\delta$, determined in [43] make the approach consistent, because the same $\delta$ was used as in that work to determine the kinetics (in fact, for estimation of $\eta_{\mathrm{p}}\left(x_{\mathrm{c}}\right)$ to account for the mass transport effects). $\delta$ mainly depends on the type of contactor and the temperature, and it can be used under various physical conditions (particle size, continuous feeding, initial bed batch, etc.). In other words, this approach makes the particle model useful for reactor simulations, consistent with the kinetics obtained at lab-scale. 
Table 2

Examples of application: char gasification with $\mathrm{CO}_{2}$ in a bench-scale bubbling FB gasifiers [42] and zinc sulphide roasting in a large-scale bubbling FB [2]

\begin{tabular}{|c|c|c|c|}
\hline & Units & $\begin{array}{l}\mathrm{CO}_{2} \text {-char gasification }\left(\mathrm{C}+\mathrm{CO}_{2} \rightarrow 2 \mathrm{CO}\right) \\
\text { (lab-scale } \mathrm{BFB} \text { ) [42] }\end{array}$ & $\begin{array}{l}\text { Zinc roaster }\left(\mathrm{ZnS}+(3 / 2) \mathrm{O}_{2} \rightarrow \mathrm{ZnO}+\mathrm{SO}_{2}\right) \\
\text { (full-scale } \mathrm{BFB})[2]\end{array}$ \\
\hline \multicolumn{4}{|l|}{ Inputs } \\
\hline \multicolumn{4}{|c|}{ Direct inputs } \\
\hline$D_{\mathrm{t}}$ & $\mathrm{m}$ & $2.66 \times 10^{-2}$ & 6.38 \\
\hline$H$ & $\mathrm{~m}$ & 0.165 & n.a. \\
\hline$T_{\mathrm{b}}$ & $\mathrm{K}$ & 1173 & 1273 \\
\hline$u_{\mathrm{mf}}$ & $\mathrm{ms}^{-1}$ & 0.19 & 0.048 \\
\hline$u_{0}$ & $\mathrm{~m} \mathrm{~s}^{-1}$ & 0.8 & 0.78 \\
\hline$c_{\text {in }}$ & $\mathrm{kmol} \mathrm{m}^{-3}$ & $2.07 \times 10^{-3}$ & $2.075 \times 10^{-3}$ \\
\hline$F_{0}$ & $\mathrm{~kg} \mathrm{~s}^{-1}$ & $1.4 \times 10^{-5}$ & 2.48 \\
\hline$x_{\mathrm{c} 0}$ & - & 0 & 0 \\
\hline$Y_{\mathrm{c} 0}$ & - & 0.85 & 1 \\
\hline$w_{\mathrm{b}}$ & $\mathrm{kg}$ & $2.5 \times 10^{-2}$ & $30,000\left(\approx w_{\mathrm{Tb}}\right)$ \\
\hline$v$ & - & 1 & $3 / 2$ \\
\hline$K_{r}$ & $s^{-1}$ & $2.3 \times 10^{-3}$ & $7.35 \times 10^{-3}$ \\
\hline$n$ & - & 0.4 & 1 \\
\hline$F_{i}\left(x_{\mathrm{c}}\right)$ & - & $\left(1-x_{\mathrm{c}}\right)$ & $\left(1-x_{\mathrm{c}}\right)^{2 / 3}$ \\
\hline$\delta$ & - & 0 & $1 / 3$ \\
\hline$d_{\mathrm{c} 0}$ & $\mathrm{~m}$ & $2.1 \times 10^{-3}$ & $6 \times 10^{-5}$ \\
\hline$\rho_{\mathrm{c} 0}$ & $\mathrm{~kg} \mathrm{~m}^{-3}$ & 800 & 4100 \\
\hline$d_{\mathrm{si}}$ & $\mathrm{kg} \mathrm{m}^{-3}$ & $4.71 \times 10^{-4}$ & $6 \times 10^{-5}$ \\
\hline$\rho_{\mathrm{si}}$ & $\mathrm{m}$ & 2650 & 3420 \\
\hline$D_{\mathrm{e}}$ & $\mathrm{m}^{2} \mathrm{~s}^{-1}$ & $7.0 \times 10^{-6}$ & $9.0 \times 10^{-6}$ \\
\hline$g\left(x_{\mathrm{c}}\right)$ & - & $\left(1-x_{\mathrm{c}}\right)^{2.5}$ & 1 \\
\hline \multicolumn{4}{|c|}{ Fluid-dynamic parameters } \\
\hline NTU & - & 7 & 1.40 \\
\hline$\beta$ & - & 0.76 & 0.99 \\
\hline \multicolumn{4}{|c|}{ Governing parameters } \\
\hline$N_{\mathrm{a}}$ & - & 0.99 & 0.76 \\
\hline$\alpha$ & - & 0.2 & 1.35 \\
\hline$D a_{\sin }$ & - & 3.78 & 88.91 \\
\hline$M_{\mathrm{in}, 0}$ & - & $2.0 \times 10^{-2}$ & $\gg 1$ \\
\hline$D a_{\text {pin }, 0}$ & - & $<1.0 \times 10^{-3}$ & $\ll 1$ \\
\hline \multicolumn{4}{|l|}{ Solution } \\
\hline$\eta_{\mathrm{ph}}$ & - & {$[\rightarrow 0]$} & 0.025 \\
\hline$D a_{\mathrm{s}} / \lambda$ & - & $0.79\left[<0.80 \approx\left(D a_{\mathrm{s}} / \lambda\right)_{\text {crit }}\right]$ & $4.05 \times 10^{-5}[\rightarrow 0]$ \\
\hline$D a_{\mathrm{R}}$ & - & $\gg 1$ & 29.08 \\
\hline$X_{\mathrm{g}}$ & - & $0.99\left[\rightarrow N_{\mathrm{a}}\right]$ & $0.74[\rightarrow(1 / \alpha)]$ \\
\hline$x_{\mathrm{c}, \mathrm{b}}$ & - & $0.23\left[\rightarrow \alpha N_{\mathrm{a}} / Y_{\mathrm{c}}\right]$ & 0.99 \\
\hline
\end{tabular}

\subsubsection{Example 2: conversion in an industrial scale $F B$ zinc} roaster. The second working example is the simulation of a zinc roaster. Details of operating conditions, stoichiometry, and geometrical parameters relevant to the fluid dynamics are presented in the last column of Table 2. The input data are directly taken from [2]. As shown in the table, the application of the method developed here is in good agreement with the classical method presented by Grace [2]. Moreover, the analysis shows that the solution is one of the limiting cases established in Fig. 6 (case (b)): solutions where $X_{\mathrm{g}} \rightarrow 1 / \alpha$ for the region of $N_{\mathrm{a}} \alpha>1$. This example is a rather "simple" one, where $n=1$ and the shrinking particle model describes the particle behaviour. In fact, an analytical solution for $\Theta\left(x_{\mathrm{c}}\right)$ can be derived for this case. The procedure developed here, can be applied, however, with any $n$ th-order kinetics with respect to the gas reactant and any empirical law for the conversion of the solids.

\subsection{Extension of the model}

The assumption of isothermicity may be valid for some systems but violated by others. Thermal gradients between phases are not expected to arise because of the good mixing generated by bubbles and the buffer role of the bed. In contrast, thermal limitations at the particle scale can be important in some cases. On the one hand, FB operations with coarse solid reactants having high reactivity and large heat of reaction are inclined to be thermally limited. In processes, such as FB combustion, temperature gradients within biomass/coal particles and/or in the boundary layer have been observed. Similarly, flash-pyrolysis of biomass and thermal decomposition of mineral rocks in FB are often thermally controlled. On the other hand, in processes like gasification of char, zinc roasting, sulphide hydrogenation of heavy metals and other NGGSR [17,23], thermal gradients are usually insignificant at both scales, so an isothermal assump- 
tion is often made. If thermal effects should be considered or not depends largely on the type of reaction, but also, on the operation conditions, the latter making it very difficult to establish general guidelines for the applicability of the model. Assessment of the presence of these potential thermal gradients prior to application of the model is, therefore, recommended. This can be made by estimation of the thermal Biot number and the maximum thermal gradient between the emulsion and particle from a heat balance over a reacting particle.

Non-isothermal analysis at a particle scale, in general, requires two further parameters to account for the thermal sensitivity of the chemical reactions (the Arrhenius parameter) and to quantify the thermal effects relative to the heat conduction (the Prater number). If, in addition, the difference between the phases is important, further parameters have to be considered by formulating an energy balance over the reactor. To account for all these phenomena in a generalised formulation such as the one presented, complicates the presentation and makes less meaningful a comprehensive analysis of governing parameters.

When more than one reaction occurs, or when the gas reactant and the product gas species further combine homogeneously or/and react with other compounds in the gas mixture, some extensions have to be made. An example is given to illustrate how reasonable simplifications can lead to application of the method. Let us consider, for instance, simultaneous $\mathrm{CO}_{2}$ and $\mathrm{H}_{2} \mathrm{O}$ gasification of char generated after devolatilisation of biomass. The relative amount of $\mathrm{H}_{2} \mathrm{O}$ and $\mathrm{CO}_{2}$ depends on previous drying, devolatilisation, and combustion processes. These processes occur at much higher rate than the gasification of the char, and so they can be calculated uncoupled to char gasification. Char reduction processes can be simplified by considering that $\mathrm{H}_{2} \mathrm{O}$ and $\mathrm{CO}_{2}$ and $\mathrm{H}_{2}$ and $\mathrm{CO}$ are lumped into the same pseudo-components, $\mathrm{R}$ and $\mathrm{P}$, respectively. As a result, the only heterogeneous reaction to be considered is char $+\mathrm{R} \rightarrow \mathrm{P}$. This reaction is assumed to occur in the emulsion phase where most char particles are found. This scheme is justified by the similar stoichiometry of char- $\mathrm{CO}_{2}$ and char- $\mathrm{H}_{2} \mathrm{O}$ and by the commonly assumed equilibrium of the WGSR (water-gas shift reaction). The relative concentrations of $\mathrm{H}_{2} \mathrm{O}$ and $\mathrm{CO}_{2}$ are adjusted to the local thermal environment around the particles, because the WGSR is more rapid. The method of this work has been applied to such a case [44], giving close agreement with results from advanced models, shortening considerable the computations, and most importantly, reducing the input data needed for the calculations.

In the method $w_{\mathrm{b}}\left(=w_{\mathrm{c}}+w_{\mathrm{A}}\right)$ has been considered known. However, when there is inert material in the bed, $w_{\text {inert }}$, this can be calculated because a pressure measurement provides the total amount of bed, $w_{\mathrm{Tb}}$ and hence, also the amount of inert material $\left(w_{\mathrm{Tb}}=w_{\mathrm{b}}+w_{\text {inert }}\right) . w_{\text {inert }}$, can be calculated once the manner of operation of the FB system is specified. As an example, let us consider an FB operating with a constant solids inventory: a continuous drainage of bed material from the system is made, and so, to keep the bed material constant, a continuous makeup of inert material is needed. At steady state, a simple mass balance over the inert material yields an additional equation for $w_{\text {inert }}$. In general, the composition of the bed has to be known for the calculation of $w_{\text {inert }}$, so this equation is coupled to the main problem, because to solve the new equation, the composition of the bed has to be known, i.e. $Y_{\mathrm{c}, \mathrm{b}}$. Therefore, $Y_{\mathrm{c}, \mathrm{b}}$ is assumed, $w_{\text {inert }}$ is calculated, and then, also $w_{\mathrm{b}}$. If the new $Y_{\mathrm{c}, \mathrm{b}}$ differs from the assumed value, a new $w_{\text {inert }}$ is estimated and the calculation is repeated until convergence. To sum up, the consideration of inert material introduces a second loop, which has to be solved in parallel with the main problem. In practise, two iterations are often enough to attain the solution because the main problem is not sensitive to this loop.

\section{Summary and conclusions}

A methodology is proposed for evaluation of general gas-solid reactions in isothermal FB. A model is developed in two stages. First, a method for evaluation of gas conversion is formulated by applying the two-phase theory of fluidisation on FB catalytic reactors, in which only gas conversion is considered. A condensed formulation is given to calculate gas conversion as a function of the governing parameters. In a second stage, the model is extended to account for non-catalytic reactions by incorporating variation of particle properties and reaction rate with conversion, as well as the distribution of the conversion of reacting particles in the bed. Three groups govern the solid and gas conversion in the reactor: (1) the ratio of reactant gas and solid feed flowrates, $\alpha$; (2) the concentration efficiency in the entire bed, $N_{\mathrm{a}}$; and (3) $D a_{\mathrm{s}} / \lambda$, being an indication of the solid conversion. The group $D a_{\mathrm{s}} / \lambda$ is obtained from a population balance taking into account the overall contribution of all reacting particles in the bed. A simplified kinetic model for a single particle is developed to characterise the governing parameters at the particle scale. Besides the intrinsic kinetics, two parameters are identified, quantifying the diffusion effects at the particle scale: a generalised Thiele module $M_{\mathrm{in}, 0}$, and a Damköhler number at a particle scale $D a_{\text {pin, } 0}$, both taking zero conversion and gas inlet conversion as reference states making these parameters known quantities. Simplification is possible for limiting values of the three principal reactor parameters $\left(\alpha, N_{\mathrm{a}}\right.$, and $\left.D a_{\mathrm{s}} / \lambda\right)$. The simplest case for NCGSR neglects the role of the distribution of conversion in the bed and allows obtaining a rapid solution for any kinetics. Examples confirmed the good results of the method. Moreover, the selection of examples allowed identification of the limiting solution derived. Discussion is also included on the application of the model to industrial FB processes, focussing on the understanding of the model limitations in order to provide guidelines for extensions. This work complements existing generalised FB reactor models for catalytic gas-solid reactions, therefore, allowing similar generalised analysis for non-catalytic gas-solid reactions.

\section{Acknowledgments}

The authors acknowledge the European Commission, the Commission of Science and Technology of Spain, and Junta de Andalusia for their financial support. The first author acknowledges the Thermal and Fluid Engineering Department at University Carlos III (Madrid) for kindly invited him to lecture 
part of the material of this article. Discussions from the lecturing sessions made, hopefully, the actual version of the paper more comprehensive and accessible.

\section{Appendix A. Frank-Kamenetskii's approximation}

Frank-Kamenetskii [45] proposed an explicit solution for the variable $y$ in a general equation of the form

$y-(1-\mu y)^{n}=0 \quad$ with $\quad 0<n<1$

where $\mu$ is a constant of any value in the interval (0-2.7). This solution is

$y= \begin{cases}\min \left(1, \frac{1}{\mu}\right) & \text { with } n=0 \\ {\left[\left(\{(1-n) \mu\}^{1 / n}+1\right)^{n}+n \mu\right]^{-1}} & \text { with } 0<n<1 \\ 2 n\left[(2 n)^{1 / n}-1+(1+2 n \mu)^{1 / n}+1\right]^{-n} & \text { with } 1<n<2.7\end{cases}$

Eqs. (21) and (29) can be expressed in the form of Eq. (A.1) where $y$ is $\eta_{\mathrm{ph}}$ or $\eta_{\mathrm{e}}$, and the corresponding values of $\mu$ are $D a_{\mathrm{R}} / N_{\mathrm{a}}$ and $D a_{\mathrm{R}} \eta_{\mathrm{i}}$. This leads to explicit solutions given by Eqs. (26) and (31) for $\eta_{\mathrm{ph}}$ and $\eta_{\mathrm{e}}$, respectively.

\section{Appendix B. Formulation of the population balance: derivation of Eq. (38)}

For bed mass and flowrate of solids, as shown in Fig. 1b, an overall steady-state mass balance in the bed gives

$F_{0}=r_{\mathrm{c}, \mathrm{b}}+F_{1}$

$r_{\mathrm{c}, \mathrm{b}}$ is defined in Eq. (7). Now, by making a balance on conversion of the particles between $x_{\mathrm{c}}$ and $x_{\mathrm{c}}+\mathrm{d} x_{\mathrm{c}}$ we have

$$
\begin{aligned}
w_{\mathrm{b}} K_{\mathrm{r}} \frac{\mathrm{d}\left(F\left(x_{\mathrm{c}}\right) p_{\mathrm{b}}\left(x_{\mathrm{c}}\right)\right)}{\mathrm{d} x_{\mathrm{c}}}= & F_{0} p_{0}\left(x_{\mathrm{c}}\right)-F_{1} p_{1}\left(x_{\mathrm{c}}\right) \\
& -w_{\mathrm{b}} R\left(x_{\mathrm{c}}\right) p_{\mathrm{b}}\left(x_{\mathrm{c}}\right)
\end{aligned}
$$

In a well mixed bed $p_{\mathrm{b}}\left(x_{\mathrm{c}}\right)=p_{1}\left(x_{\mathrm{c}}\right)$. Solving for the distribution of conversion in the bed $p_{\mathrm{b}}\left(x_{\mathrm{c}}\right)$ yields [10]:

$$
\begin{aligned}
& \frac{\mathrm{d} p_{\mathrm{b}}\left(x_{\mathrm{c}}\right)}{\mathrm{d} x_{\mathrm{c}}}+\left[\frac{\mathrm{d} \ln F\left(x_{\mathrm{c}}\right)}{\mathrm{d} x_{\mathrm{c}}}+\frac{1}{\lambda F\left(x_{\mathrm{c}}\right)}+\frac{1}{1 / Y_{\mathrm{c} 0}-x_{\mathrm{c}}}\right] p_{\mathrm{b}}\left(x_{\mathrm{c}}\right) \\
& =\frac{1}{D a_{\mathrm{s}}} \frac{p_{0}\left(x_{\mathrm{c}}\right)}{F\left(x_{\mathrm{c}}\right)}
\end{aligned}
$$

where $D a_{\mathrm{s}}$ and $\lambda$ are dimensionless parameters defined in Eqs. (40) and (41). Eq. (B.3) is integrated using the condition $p_{\mathrm{b}}(0)=0$ to obtain

$p_{\mathrm{b}}\left(x_{\mathrm{c}}\right)=\frac{1}{D a_{\mathrm{s}}} \frac{1 / Y_{\mathrm{c} 0}-x_{\mathrm{c}}}{F\left(x_{\mathrm{c}}\right)} \int_{0}^{x_{\mathrm{c}}}\left(\exp \left[\frac{-\Theta(s)}{\lambda}\right] \frac{p_{0}(s)}{1 / Y_{\mathrm{c} 0}-s}\right) \mathrm{d} s$

Assuming that all the particles enter with the same conversion $x_{\mathrm{c} 0}$, the feed distribution is $p_{0}\left(x_{\mathrm{c}}\right)=\delta\left(x_{\mathrm{c}}-x_{\mathrm{c} 0}\right)$ and Eq. (B.4) is simplified to give Eq. (38).

\section{References}

[1] W.G. May, Fluidized bed reactors studies, Chem. Eng. Prog. 55 (1959) $49-56$.

[2] J.R. Grace, Fluid beds as chemical reactors, in: D. Geldart (Ed.), Gas Fluidization Technology, John Wiley \& Sons Ltd., 1986, pp. 285-339.

[3] J.C. Orcutt, J.F. Davidson, R.L. Pigford, Reaction time distributions in fluidized bed reactors, Chem. Eng. Prog. Symp. Ser. 59 (1962) 1-15.

[4] J.F. Davidson, D. Harrison, Fluidised Particles, Cambridge University Press, London, 1963.

[5] M. Horio, C.Y. Wen, An assessment of fluidized-bed modelling, AIChE Symp. Ser. 73 (1977) 9-21.

[6] W.P.M. van Swaaij, Chemical reactors, in: J.F. Davidson, R. Clift, D. Harrison (Eds.), Fluidization, 2nd edition, Academic Press, London, 1985, pp. 595-629, Chapter 18.

[7] J.F. Davidson, D. Harrison, R.C. Darton, R.D. LaNauze, The two-phase theory of fluidization and its application to chemical reactors, in: L. Lapidus, N.R. Amundson (Eds.), Chemical Reactor Theory, A Review, PrenticeHall, Englewood Cliffs, NJ, 1977, pp. 583-685.

[8] C. Chavarie, J.R. Grace, Performance analysis of a fluidized bed reactor. II. Observed reactor behavior compared with simple two-phase models, Ind. Eng. Chem. Fund. 14 (1975) 79-86.

[9] H.S. Caram, N.R. Amundson, Fluidized bed gasification reactor modeling. 1. Model description and numerical results for a single bed, Ind. Eng. Chem. Proc. Des. Dev. 18 (1978) 80-96.

[10] H.S. Caram, N.R. Amundson, Fluidized bed gasification reactor modeling. 2. Effect of the residence time distribution and mixing of particles. Staged bed modelling, Ind. Eng. Chem. Proc. Des. Dev. 18 (1978) 96102.

[11] N. Mostoufi, H.P. Cui, J. Chaouki, A comparison of two- and single-phase models for fluidized bed reactors, 2001, Ind. Eng. Chem. Res. 40 (2001) 5526-5532.

[12] D. Kunii, O. Levenspiel, Fluidization Engineering, 2nd edition, Butterworth-Heinemann, London, 1991.

[13] R.K. Irani, B.D. Kulkarni, L.K. Doraiswamy, Analysis of complex reaction schemes in a fluidized bed. Application of the Kunii-Levenspiel model, Ind. Eng. Chem. Proc. Des. Dev. 19 (1980) 24-30.

[14] T.P. Chen, S.C. Saxena, Mathematical modelling of coal combustion in fluidized beds with sulphur-emission control by limestone or dolomite, Fuel 56 (1977) 401-413.

[15] B.W. Overturf, Toward a general description of gas-solid reactions in a fluidised bed reactor, Ph.D. Dissertation, University of Purdue, 1980.

[16] J.G. Yates, Fundamentals of Fluidized-bed Chemical Processes, Butterworths, London, 1983

[17] L.K. Doraiswamy, M.M. Sharma, Heterogeneous Reactions. Analysis, Examples and Reactor Design, vol. 1, Wiley, New York, 1984.

[18] A.B.M. Heesink, J. Klaus, W.P.M. Van Swaaij, Influence of particle residence time distribution on the reactivity in fluidized bed reactors, Chem. Eng. Sci. 49 (1994) 2243-2261.

[19] L. Liliedahl, K. Sjöström, Modelling of char-gas reaction kinetics, Fuel 76 (1997) 29-37.

[20] S. Dutta, C.Y. Wen, R.J. Belt, Reactivity of coal and char. 1. In carbon dioxide atmosphere, Ind. Eng. Chem. Proc. Des. Dev. 16 (1977) 20-30.

[21] H. Huang, A.P. Watkinson, Coal gasification in a stirred bed reactor, Fuel 75 (1997) 1617-1674.

[22] T. Adschiri, T. Shiraha, T. Kojima, T. Furusawa, Prediction of $\mathrm{CO}_{2}$ gasification rate of char in fluidized-bed gasifier, Fuel 65 (1986) 1688-1693.

[23] J. Szekely, J.W. Evans, H.Y. Sohn, Gas-Solid Reactions, Academic Press, New York, 1976.

[24] F.G. van den Aarsen, Fluidised bed wood gasifier. Performance and modelling, Ph.D. Dissertation, Twente University Publication, University of Twente, 1985

[25] S.K. Bhatia, D.D. Perlmutter, A random pore model for fluid-solid reactions. I. Isothermal, kinetic control, AIChE J. 26 (1980) 379-386.

[26] G.A. Simons, The unified coal-char reaction, Fuel 59 (1980) 143-144.

[27] J.L. Johnson, Kinetics of Coal Gasification, Wiley, New York, 1979.

[28] N.C. Gardner, E. Samuels, K. Wilks, Catalysed hydrogasification of coal chars, Adv. Chem. Ser. 131 (1974) 217-236. 
[29] E. Chornet, J.M. Baldoroso, H.T. Tarki, Kinetic expressions for coal chargas reactions, Fuel 58 (1979) 395-397.

[30] S. Kasaoka, Y. Sakata, C. Tong, Kinetic evaluation of the reactivity of various coal chars for gasification with carbon dioxide in comparison with steam, Int. Chem. Eng. 25 (1985) 160-175.

[31] N.M. Laurendeau, Heterogeneous kinetics of coal char gasification and combustion, Prog. Energy Combust. Sci. 4 (1978) 221-270.

[32] A. Gómez-Barea, P. Ollero, R. Arjona, Reaction-diffusion model of TGA gasification experiments for estimating diffusional effects, Fuel 84 (2005) $1695-1704$

[33] A. Gómez-Barea, P. Ollero, B. Leckner, Mass transport effects during measurements of gas- solid reaction kinetics in a fluidised bed, Chem. Eng. Sci. 62 (2007) 1477-1493.

[34] S.O. Oka, Fluidised Bed Combustion, Marcel Dekker Inc., New York, 2004.

[35] G.F. Froment, K.B. Bischoff, Chemical Reactor Analysis and Design, 2nd edition, Wiley, New York, 1990.

[36] O. Levenspiel, D. Kunii, T. Fitzgerald, The processing of solids of changing size in bubbling fluidized beds, Powder Technol. 2 (1968) 87-96.

[37] G. Marbán, A.B. Fuertes, J.J. Pis, Calculation of burnoff distributions of char particles in a bubbling fluidized bed reactor by means of batch combustion experiments, Chem. Eng. Res. Des. 76 (1998) 864-872.
[38] B. Srinivas, N.R. Amundson, A single-particle char gasification model, AIChE J. 26 (1980) 487-496.

[39] J.I. Morell, N.R. Amundson, S.K. Park, Dynamics of a single particle during char gasification, Chem. Eng. Sci. 45 (1990) 387-401.

[40] C.Y. Wen, Noncatalytic heterogeneous solid fluid reactions, Ind. Eng. Chem. 60 (1968) 34-54.

[41] G. Brem, J.J.H. Brouwers, Analytical solutions for non-linear conversion of a porous solid particle in a gas. I. Isothermal conversion, Chem. Eng. Sci. 45 (1990) 1905-1913.

[42] A. Gomez-Barea, B. Leckner, P. Ollero, C. Fernandez-Baco, L. Salvador, Reduction of physical effects during reactivity tests in fluidized bed, Ind. Eng. Chem. Res. 45 (2006) 7344-7350.

[43] A. Gómez-Barea, Modelling of diffusional effects during gasification of biomass char particles in fluidised-bed, Ph.D. Dissertation, University of Seville, Spain, 2006.

[44] A. Gómez-Barea, B. Leckner, M. Campoy, Conversion of char in CFB gasifiers, in: E.-U. Hartge (Ed.), Proceedings of 9th International Conference on Circulating Fluidized Beds, Hamburg, Germany, 2008.

[45] D.A. Frank-Kamenetskii, Diffusion and Heat Exchange in Chemical Kinetics, Princeton University Press, Princeton, 1955. 